\title{
Female labour market participation in Europe: novel evidence on trends and shaping factors
}

\author{
Angela Cipollone ${ }^{1}$, Eleonora Patacchini ${ }^{2}$ and Giovanna Vallanti ${ }^{3 *}$
}

\footnotetext{
*Correspondence: gvallanti@luiss.it ${ }^{3}$ LUISS University, LLEE and CeLEG, Rome, Italy

Full list of author information is available at the end of the article
}

\begin{abstract}
We investigate the changes in women's participation patterns across 15 EU countries over the last 20 years using individual data from ECHP and EUSILC databases. Our findings show that the observed trends in female participation differ substantially both across countries and across different groups of women. We explore such heterogeneity in trends by looking at the effects of policies and labour market institutional factors on the participation of women with different family and individual characteristics. Our estimates reveal a role of policies and institutions that is stronger than what has so far been assessed. Labour market institutions and family-oriented policies explain almost $25 \%$ of the actual increase in labour force participation for young women, and more than 30\% for highly educated women. Surprisingly, changes in the institutional and policy settings contribute less in explaining the participation of low-skilled women. We also find that reforming the institutional framework towards a model of "flexicure" labour market is effective in enhancing women labour supply only when deregulation is accompanied by sufficient social compensation.
\end{abstract}

JEL Classification: J11, J21, J2

Keywords: Employment gender gap; Labor market institutions; Child-rearing; Elderly care; Flexicurity

\section{Introduction}

The importance given to the protection of Human Rights and fundamental freedoms in the European Community Treaties has changed considerably since the European venture was first launched. Since 1975, a series of directives have broadened the principle of equality between men and women to cover working conditions, training and promotion, social security, access to goods and services, maternity protection and parental leave. In 1997, the Amsterdam Treaty enabled the gender dimension to be integrated into all Community policies and established the principle of equal treatment as a fundamental right. Since then, the Member States have introduced different policies and activities fighting gender inequalities ${ }^{1}$.

As a matter of fact, the female participation rate in Europe has increased from around $55 \%$ in the early 1990 s to more than $66 \%$ in 2008 . In the same period, female employment rate has moved in the same direction, by increasing from $49 \%$ to $61 \%$. This steady improvement in women labour market position has led to a significant decline in the gender employment gap, which has nearly halved since 1990 , from more than $25 \%$ to almost $14 \%$ in $2008^{2}$.

(O2014 Cipollone et al.; licensee Springer. This is an Open Access article distributed under the terms of the Creative Commons Attribution License (http://creativecommons.org/licenses/by/2.0), which permits unrestricted use, distribution, and reproduction in any medium, provided the original work is properly credited. 
The extent to which reforms and labour market institutions have contributed to such a pattern is at the forefront of the political debate. Although there is a variety of studies looking at this issue from different perspectives, the available evidence is still inconclusive (see Costa, 2000 and Del Boca and Locatelli, 2006 for recent reviews). These patterns could be driven by changes in cultural attitudes towards work especially in countries where participation is traditionally lower ${ }^{3}$. Changes in the characteristics of the female population such as fertility decisions, elderly care responsibilities ${ }^{4}$, educational choices ${ }^{5}$ and demographic changes ${ }^{6}$ could also have impacted these patterns.

Most of the studies looking at the evolution of the employment (or wage) gender gap over time using individual data focus on a single country only, thus failing to capture important differences across European countries characterized by different welfare structures and cultural attitudes towards female labour market participation. Conversely, cross-country comparisons using aggregate data typically fail to distinguish compositional effects (i.e. those arising from changes in the socio- demographic characteristics of men and women over time) and to capture the varying responsiveness of women with different individual characteristics to changes in the institutional setting (Jaumotte 2003; Genre et al. 2010).

In this paper we combine the micro and macro approaches into a unified empirical design, by investigating the changes in female participation patterns across $15 \mathrm{EU}$ countries over the last 20 years using individual data from ECHP and EUSILC databases. There are two main contributions of our approach. First, we use individual data for an unusually large set of countries and for a long time period (twenty years). Second, we provide a quantification of the role of labour market institutional factors which is more precise than in previous studies.

We begin with an exploratory analysis of the data where individual information is used to compute aggregate trends. Next, we use a regression analysis to understand whether the impact of individual characteristics on labour market participation varies across time and across countries with different welfare regimes. Finally, we further these results by exploiting a multi-level model specification to appreciate how institutional and policy factors affect the choice between unpaid family responsibility (child rearing and elderly care) and paid occupation for women in different age and education groups.

Our findings point towards a strict interplay between individual characteristics and the institutional and policy setting, revealing a role of institutional factors that is stronger than what has so far been assessed. According to our results, the attitude to work of young women with children appears to be favoured by policies aimed at supporting family and by the expansion of flexible forms of employment (especially in terms of fixed term contracts) to the extent that such forms of employment are not perceived to be of low quality. Moreover, in line with the flexicurity approach (an integrated strategy to simultaneously enhance flexibility and security in the labour market), we find that labour market flexibility is associated with higher female participation only when it is accompanied by a certain degree of social security.

We finally quantify the extent to which changes in the labour market behaviour of women with specific characteristics (e.g. young children) can be associated to changes in policies and institutions. Labour market reforms and changes of social policies predict almost $25 \%$ of the actual increase in labour force participation for young women, and more than $30 \%$ for highly educated women. However, labour market reforms appear less related to the observed labour market participation of low skilled women. This result is 
apparently in contrast with the existing empirical evidence which shows that less educated women (with a lower attachment to work) are more responsive to work incentives created by policy/institutional changes (Del Boca et al. 2009). Nevertheless, we argue that in many European countries, labour market reforms are associated with a deterioration of job quality, especially for low educated women, increasing the risk of dropping out from the labour force ${ }^{7}$.

The paper is organized as follows. In Section 2 we discuss the relevance of the institutional context in shaping female choices between unpaid family responsibility and paid occupation and define our research questions. Section 3 describes the data and summarizes the large quantity of micro-level information available for different European countries and across time using synthetic indicators of female labour market performance. Section 4 contains the results of a regression analysis of female involvement in the labour market across time and countries, whereas Section 5 analyses more closely the role of the labour market institutional framework and social policies. Section 6 concludes.

\section{Family responsibility, paid work and institutions}

A large empirical literature provides evidence that the provision of facilities, parental leaves and subsidies for day-care spaces and, more generally, policies aimed at alleviating the financial burden of child-rearing have a positive effect on female labour market integration by either increasing work attachment (fewer women leaving occupation after childbirth) or facilitating female re-entry into the labour market as children grow up (see, e.g., Sànchez-Mangas and Sànchez-Marcos, 2008; Lefebvre et al. 2009).

Unlike research on child care policies, there is still little evidence on the role of elderly care policies and norms on female attitude to paid work ${ }^{8}$. Policies and practices favouring the reconciliation of child care and employment may not be easily transferred to elderly care. First, caring responsibilities for elderly usually occur at a later phase of work career than child care. Second, elderly care is less predictable in timing, duration and intensity (Keck and Saraceno 2010). Theoretically, the presence of monetary subsidies and publicly financed elderly care services may have a positive effect on the choice of staying in the labour force. On the other hand, unconditional cash transfers for elderly care, when combined with other sources of income, such as the dependent elderly's pension, may create an "incentive trap" by reducing the opportunity cost of informal care, thereby exerting a negative impact on labour market participation of low income and low educated women (Simonazzi 2009)

In addition to fiscal and social policies for the support of working mothers/elderly carers, the role played by more general changes in the institutional context is gaining increasing attention in the political debate. In the last two decades, the labour markets of many European countries have experienced deep changes towards the promotion of a flexicurity model of labour market with the aim of increasing competitiveness, creating employment and redistributing work. Though the idea of deregulation was the common factor behind the waves of reforms, the promotion of flexicurity was pursued through very different types of interventions on both the flexibility and security side. In the Social Democratic countries, reforms were mainly aimed at reducing the protection of insiders by lowering the degree of employment protection on regular forms of employment on the one hand, and increasing income security on the other. In the Southern countries and some Continental countries, flexibility has been obtained through marginal reforms 
which aimed at deregulating the use of temporary or "atypical" forms of employment while leaving largely unchanged the legislation applying to the stock of workers employed under permanent (open-ended) contracts. In other countries, such as the Netherlands, the emphasis of the reforms was to promote flexible work hours and part-time arrangements. Such reforms can be regarded as beneficial to women to the extent that they facilitate labour market integration. However, this integration may occur at the risk of a reinforcement of the traditional separation of gender roles in the labour market and within the family.

From the flexibility side, the link between labour market deregulation and female participation is not clear-cut, though there are a number of empirical studies which show that the negative effects of strict Employment Protection Legislations (EPL) are disproportionately larger for those individuals (such as prime-age women) who are more subject to labour market entry problems. As a result, in a rigid labour market, employment opportunities for prime age women are significantly reduced because they are more likely than men to move between employment and inactivity due to the competing demands of work and family life (OECD 2004; Heckman and Pages 2000). From the security side, whether or not the presence of a generous system of unemployment benefits accompanied by active (and activation) policies increases incentives to work largely depends on the eligibility requirements. In many countries, the access to social security and that to active labour policies are linked and depend on work history (for example, contribution records showing recent and continuous employment). This requirement may represent a barrier for women who are more likely to have interrupted careers and to work part-time. This implies that, while the burden of flexibility is increasingly borne by women, women are also more likely to be excluded from benefits and active policies. Thus, if women are in principle supposed to benefit from the combination of flexibility in the labour market and security in the social system, the tendency towards a more flexible labour market may exert a negative impact on the incentives to participate when flexible occupations are of lower quality and poorly securitized.

In this paper, we investigate the role of welfare regime-specific characteristics in explaining the observed trends in female labour market performance. We model two dimensions of welfare regimes: (1) the social policies in support to families involved in informal care, both child-care and elderly care, and (2) the institutional characteristics of the labour market in terms of the degree of flexibility and security.

More specifically, we test two main hypotheses:

$\mathrm{H}_{1}$ : social policies for the support of families with young children (including maternity, parental and childcare leaves) and dependent elderly persons positively correlate with female participation by weakening the trade-off between informal care and paid work and positively affecting female labour market participation;

$\mathrm{H}_{2}$ : changes in the institutional setting towards a model characterized by lower barriers to hiring and firing combined with a higher social protection (passive labour market policies and active labour market policies) positively correlate with female labour market activity and this correlation is larger for women who are more involved in family (unpaid) occupations.

We will refer to the variables capturing the characteristics of institutional context and policies as "macro" factors. 


\section{Data and exploratory evidence}

\subsection{The data}

We combine micro data from two different sources, the ECHP (European Community Household Panel) and the EU-SILC (European Union Statistics on Income and Living Conditions), to create a unique dataset of comparable household and individual level characteristics across countries and over time.

The ECHP micro data is a household survey with a common framework conducted across the EU-15 Member States under the supervision of Eurostat. The total duration of the ECHP is 8 years, running from 1994 to $2001^{9}$. The dataset includes information on family size and composition, living conditions and several income measures. Therefore, it provides a source of mutually comparable information at individual level for the EU member countries at the turn of the twentieth and twenty-first centuries.

EU-SILC (European Union Statistics on Income and Living Conditions) is the successor of the ECHP. The EU-SILC provides harmonized cross-sectional and longitudinal multidimensional micro data on income and social exclusion in the European countries, and it is the largest comparative survey of European income and living conditions ${ }^{10}$.

In order to obtain a unique dataset of comparable household and individual level characteristics across the EU countries within the whole period 1994-2009, we limit our analysis to the EU-15 Member States ${ }^{11}$. The overall sample includes 1,657,367 individuals between 25 and 64 years old of which 851,010 women and 806,357 men. A list of the variables used in this study, as well as summary statistics for the women and men samples, are reported in Tables 1 and 2. The employment and participation rates stand at $59 \%$ and $66 \%$, respectively, for the female sample, and increase to approximately $80 \%$ and $86 \%$, respectively, for the male sample. The percentage of highly educated women and men (with at least a college degree, "ISCED 6-7") is $27 \%$ and women are slightly more represented than men among the lowest educated individuals (with less than upper secondary school, "ISCED 0-2"). Over $65 \%$ of respondents in both samples declare to live in-couple. $42 \%$ of women and $23 \%$ of men live in households with at least one child under 14 years old; $18 \%$ of those individuals with children under 14 years old live in households with at least one pre-school age child. Co-living with elderly (that is, individuals with 70 years old or more) involves just $6 \%$ of all individuals in our sample. Approximately $28 \%$ of those living in couple have a partner with a lower secondary education (ISCED 0-2), 26\% of them have a partner with an upper secondary education (ISCED 3-5), $20 \%$ of individuals have a highly educated partner (ISCED 6-7). The variable "cycle" measures the business cycle frequencies of national GDP over the survey years, 1994-2009. This variable has been obtained by implementing the filter proposed by Hodrick and Prescott (1997).

\subsection{A micro-data-based cross country comparison}

We begin our analysis by providing some preliminary evidence of the changes in the gender gap in terms of participation and unemployment. Using data from the OECD labour Force Statistics, Figures 1 and 2 show the evolution of activity rates and unemployment rates in the different European countries separated by gender. Figure 1 points towards the well-known onset of female labour market participation, especially in countries with a traditionally low attachment of women to the labour market such as Greece, Ireland, Italy and Spain. Interestingly, Figure 2 shows that the unemployment rates do not exhibit 
Table 1 Summary statistics: female sample

\begin{tabular}{|c|c|c|c|c|c|c|}
\hline & Variable & Obs & Mean & Std. Dev. & Min & Max \\
\hline \multirow{12}{*}{ Individual characteristics } & Employed & 851010 & 0.594 & 0.491 & 0 & 1 \\
\hline & Active & 851010 & 0.656 & 0.475 & 0 & 1 \\
\hline & Male & 851010 & 0 & 0 & 0 & 0 \\
\hline & Age & 851010 & 44.269 & 11.078 & 25 & 64 \\
\hline & ISCED02 & 832447 & 0.382 & 0.486 & 0 & 1 \\
\hline & ISCED35 & 832447 & 0.344 & 0.475 & 0 & 1 \\
\hline & ISCED67 & 832447 & 0.274 & 0.446 & 0 & 1 \\
\hline & Single & 844864 & 0.189 & 0.392 & 0 & 1 \\
\hline & Incouple & 844864 & 0.687 & 0.464 & 0 & 1 \\
\hline & Separated & 844864 & 0.018 & 0.132 & 0 & 1 \\
\hline & Divorced & 844864 & 0.067 & 0.25 & 0 & 1 \\
\hline & Widowed & 844864 & 0.039 & 0.193 & 0 & 1 \\
\hline \multirow{10}{*}{ Household characteristics } & Children & 851010 & 0.713 & 1.008 & 0 & 15 \\
\hline & Child & 851010 & 0.422 & 0.494 & 0 & 1 \\
\hline & child06 & 851010 & 0.179 & 0.383 & 0 & 1 \\
\hline & child03 & 851010 & 0.096 & 0.295 & 0 & 1 \\
\hline & child36 & 851010 & 0.113 & 0.317 & 0 & 1 \\
\hline & child614 & 851010 & 0.259 & 0.438 & 0 & 1 \\
\hline & old70 & 851010 & 0.06 & 0.238 & 0 & 1 \\
\hline & plSCED02 & 851010 & 0.276 & 0.447 & 0 & 1 \\
\hline & plSCED35 & 851010 & 0.258 & 0.438 & 0 & 1 \\
\hline & plSCED67 & 851010 & 0.198 & 0.398 & 0 & 1 \\
\hline \multirow{2}{*}{ Trend } & Year & 851010 & 2003 & 4.983 & 1994 & 2009 \\
\hline & Cycle & 842730 & 0.006 & 1.958 & -8.636 & 4.172 \\
\hline \multirow{15}{*}{ Country of residence } & DK & 851010 & 0.044 & 0.206 & 0 & 1 \\
\hline & $\mathrm{NL}$ & 851010 & 0.07 & 0.255 & 0 & 1 \\
\hline & $\mathrm{BE}$ & 851010 & 0.045 & 0.207 & 0 & 1 \\
\hline & $\mathrm{FR}$ & 851010 & 0.074 & 0.262 & 0 & 1 \\
\hline & $\mathrm{IE}$ & 851010 & 0.043 & 0.203 & 0 & 1 \\
\hline & IT & 851010 & 0.156 & 0.362 & 0 & 1 \\
\hline & GR & 851010 & 0.06 & 0.237 & 0 & 1 \\
\hline & ES & 851010 & 0.111 & 0.314 & 0 & 1 \\
\hline & PT & 851010 & 0.054 & 0.227 & 0 & 1 \\
\hline & AT & 851010 & 0.043 & 0.204 & 0 & 1 \\
\hline & $\mathrm{Fl}$ & 851010 & 0.068 & 0.252 & 0 & 1 \\
\hline & SE & 851010 & 0.048 & 0.213 & 0 & 1 \\
\hline & DE & 851010 & 0.087 & 0.282 & 0 & 1 \\
\hline & LU & 851010 & 0.035 & 0.183 & 0 & 1 \\
\hline & UK & 851010 & 0.062 & 0.241 & 0 & 1 \\
\hline
\end{tabular}

- ISCED02 (pISCED02): lower secondary education of the woman (of her partner); ISCED35 (pISCED35): upper secondary education of the woman (of her partner); ISCED67 (pISCED67): tertiary education of the woman (of her partner).

- DK-Denmark, NL-Netherlands, BE-Belgium, FR-France, IE-Ireland, IT-Italy, GR-Greece, ES-Spain, PT-Portugal, AT-Austria,

FI-Finland, SE-Sweden, DE-Germany, LU-Luxembourg, UK-United Kingdom.

similarly marked trends. This evidence thus seems to suggest that the relevant achievements of women in terms of labour market performance are to be attributed to the supply side of the market. In fact, the increase in female activity rate originates from an increase of female employment due to the increased willingness of women to work rather than from a decrease in the unemployment rate. However, the relevant question that these aggregate indicators are not able to answer is how much of these trends can be attributed 
Table 2 Summary statistics: male sample

\begin{tabular}{|c|c|c|c|c|c|c|}
\hline & Variable & Obs & Mean & Std. Dev. & Min & $\operatorname{Max}$ \\
\hline \multirow{12}{*}{ Individual characteristics } & Employed & 806357 & 0.797 & 0.4020 & 1 & \\
\hline & Active & 806357 & 0.857 & 0.35 & 0 & 1 \\
\hline & Male & 806357 & 1 & 0 & 1 & 1 \\
\hline & Age & 806357 & 44.229 & 11.137 & 25 & 64 \\
\hline & ISCED02 & 788367 & 0.36 & 0.48 & 0 & 1 \\
\hline & ISCED35 & 788367 & 0.368 & 0.482 & 0 & 1 \\
\hline & ISCED67 & 788367 & 0.273 & 0.445 & 0 & 1 \\
\hline & Single & 799834 & 0.257 & 0.437 & 0 & 1 \\
\hline & Incouple & 799834 & 0.675 & 0.468 & 0 & 1 \\
\hline & Separated & 799834 & 0.013 & 0.112 & 0 & 1 \\
\hline & Divorced & 799834 & 0.046 & 0.209 & 0 & 1 \\
\hline & Widowed & 799834 & 0.01 & 0.098 & 0 & 1 \\
\hline \multirow{10}{*}{ Household characteristics } & Children & 806357 & 0.435 & 0.925 & 0 & 14 \\
\hline & Child & 806357 & 0.225 & 0.418 & 0 & 1 \\
\hline & child06 & 806357 & 0.18 & 0.384 & 0 & 1 \\
\hline & child03 & 806357 & 0.1 & 0.3 & 0 & 1 \\
\hline & child36 & 806357 & 0.112 & 0.315 & 0 & 1 \\
\hline & child614 & 806357 & 0.244 & 0.43 & 0 & 1 \\
\hline & old70 & 806357 & 0.061 & 0.239 & 0 & 1 \\
\hline & plSCED02 & 806357 & 0.278 & 0.448 & 0 & 1 \\
\hline & plSCED35 & 806357 & 0.261 & 0.439 & 0 & 1 \\
\hline & plSCED67 & 806357 & 0.198 & 0.398 & 0 & 1 \\
\hline \multirow{2}{*}{ Trend } & Year & 806357 & 2003 & 4.985 & 1994 & 2009 \\
\hline & Cycle & 798435 & 0.012 & 1.959 & -8.636 & 4.172 \\
\hline \multirow{15}{*}{ Country of residence } & DK & 806357 & 0.045 & 0.207 & 0 & 1 \\
\hline & $\mathrm{NL}$ & 806357 & 0.068 & 0.253 & 0 & 1 \\
\hline & BE & 806357 & 0.044 & 0.205 & 0 & 1 \\
\hline & $F R$ & 806357 & 0.073 & 0.261 & 0 & 1 \\
\hline & $\mathrm{IE}$ & 806357 & 0.043 & 0.202 & 0 & 1 \\
\hline & IT & 806357 & 0.159 & 0.366 & 0 & 1 \\
\hline & GR & 806357 & 0.06 & 0.238 & 0 & 1 \\
\hline & ES & 806357 & 0.111 & 0.314 & 0 & 1 \\
\hline & PT & 806357 & 0.053 & 0.224 & 0 & 1 \\
\hline & AT & 806357 & 0.043 & 0.203 & 0 & 1 \\
\hline & $\mathrm{Fl}$ & 806357 & 0.073 & 0.26 & 0 & 1 \\
\hline & SE & 806357 & 0.049 & 0.216 & 0 & 1 \\
\hline & $\mathrm{DE}$ & 806357 & 0.083 & 0.276 & 0 & 1 \\
\hline & LU & 806357 & 0.036 & 0.187 & 0 & 1 \\
\hline & UK & 806357 & 0.059 & 0.235 & 0 & 1 \\
\hline
\end{tabular}

\ISCED02 (pISCED02): lower secondary education of the woman (of her partner); ISCED35 (pISCED35): upper secondary education of the woman (of her partner); ISCED67 (pISCED67): tertiary education of the woman (of her partner).

"DK-Denmark, NL-Netherlands, BE-Belgium, FR-France, IE-Ireland, IT-Italy, GR-Greece, ES-Spain, PT-Portugal, AT-Austria,

FI-Finland, SE-Sweden, DE-Germany, LU-Luxembourg, UK-United Kingdom.

to forces which are not related to the increased similarity between women and men in terms of socio- demographic factors such as, for example, education. Such changes in outcomes over and above those stemming from natural demographic trends across countries and over time are of particular interest for policy purposes as they might be the consequence of reforms in the institutional setting.

In our analysis, we use micro data to disentangle aggregate trends into different sources. 

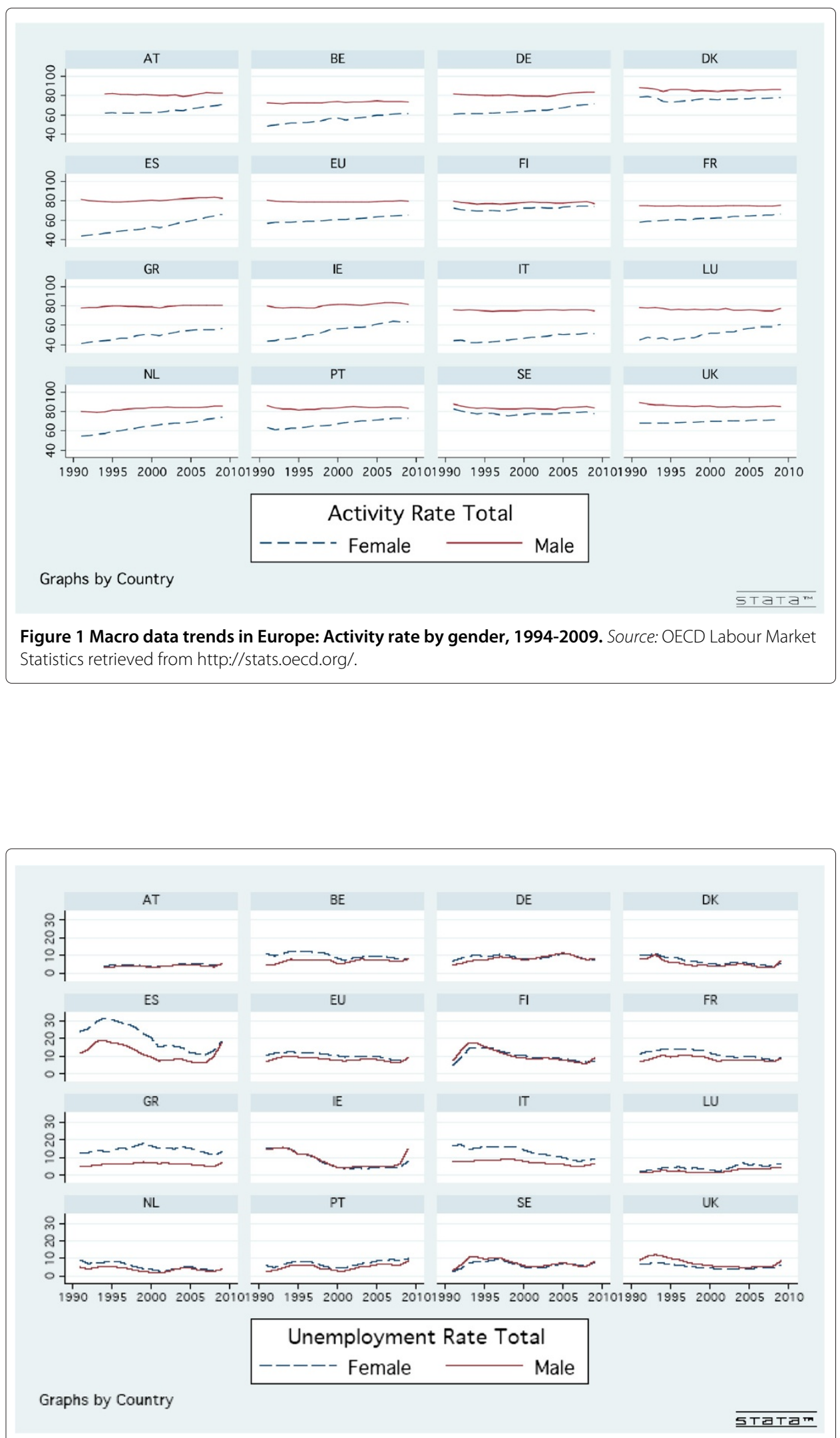

Figure 2 Macro data trends in Europe: Unemployment rate by gender, 1994-2009. Source: OECD Labour Market Statistics retrieved from http://stats.oecd.org/. 
We start by looking at the extent to which women differ from men along two different labour market indicators (participation and unemployment) across selected European countries, controlling for the influence of demographic and social characteristics. We use the methodology introduced by Vidgor (2008) to measure differences between native and immigrants in US states along cultural and economic lines. Such an approach allows us to summarize the large quantity of micro-level information available across European countries and over time in a way that eases cross-country comparisons ${ }^{12}$. In words, the procedure predicts which individuals are women on the basis of observed characteristics and then uses this finding to measure the gap between men and women for a chosen outcome - such as the activity rate - by constructing a numeric index. Such an index ranges between 0 and 1. It can be interpreted as an index of dissimilarity: the larger the distance from 1, the more females are different from men along the inspected labour market indicator, controlling for other individual characteristics. More specifically, we control for differences in demographic factors using individual information on age and education level as well as in family structure using marital status, partner education, and number of children. A value of 1 for the index indicates that, if those characteristics were equal between men and females, women and men would not differ in terms of the chosen labour market outcome. Departing from 1 indicates that there are other forces (other than those stemming from natural demographic trends) which make female labour market performance worse than that of men.

We construct two different indices capturing gaps between women and men in labour market participation (activity gap index) and unemployment (gap index for those in the labour force) (see Appendix A). The activity index captures differences between women and men inside and outside the labour market, thus revealing behavioural differences more likely to come from the supply side of the labour market. The unemployment index focuses on gender differences for the individuals in the labour market only, and hence captures the behavioural differences more likely to come from the demand side.

Figures 3 and 4 show the results (the complete list of results is collected in Additional file 1 Tables S1-S2) ${ }^{13}$. They reveal important cross-country differences in the determinants of the aggregate trends that were not captured in Figures 1 and 2. It appears that in most of the countries with a significant reduction in the gender gap (such as the Mediterranean countries, plus Ireland; Figure 1) changes in demographic and social characteristics (i.e. the increasing similarity between women and men in terms of observable individual characteristics) cannot explain all the shrinking in the gap. Indeed, our corresponding micro-based gender gap indices in Figure 3 remain far from 1, although they are increasing towards 1 over time. This evidence suggests that there are other forces which contributed to the observed remarkable increase in female involvement in the labour market. Similarly, the reduced gender gap in unemployment rates in Spain and the Netherlands (Figure 2) is associated with significant movements in our micro-based gender gap indices in Figure 4, indicating a limited role for changes in the female labour force composition. On the other hand, the marked changes in female unemployment in Italy and Finland (Figure 2) seem to be mainly associated with demographic trends and other characteristics of the female labour force factors rather than to changes in preferences, beliefs or labour market policies. Indeed, when controlling for these factors, i.e. when looking at the results obtained using our indicators in Figure 4, changes in the unemployment gap between men and women in those countries are not statistically significant. 

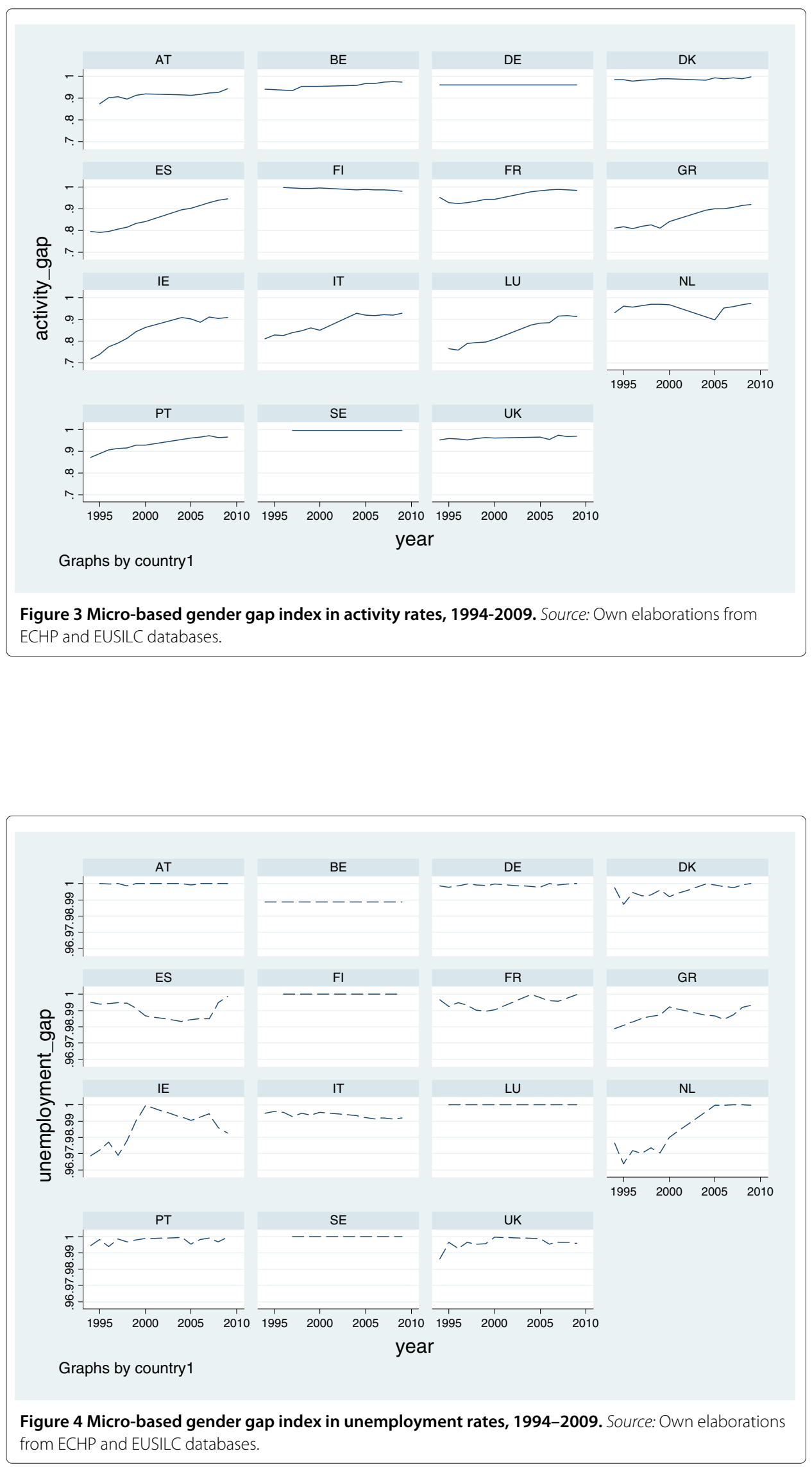
We now focus on the information provided by our different indices. Interestingly, it shows a feature that is common to most of the European countries: the marked changes in our micro-based gender gap index in activity rates are associated with a substantial stability of the same index in unemployment rates. This finding reveals that the observed changes in unemployment rates (or employment rates for those participating to the labour force) largely reflect changes in demographic and social factors, whereas other forces seem to shape female participation rates. This evidence thus seems to provide some support to the idea that female participation rates are driven by changes in countryspecific characteristics, such as institutional reforms and cultural attitudes towards work. As stressed in the introduction, the importance of these factors in influencing labour market performance is gaining attention among economists.

In conclusion, our micro-based gender gap indices in activity and unemployment rates show a relevant degree of cross-countries heterogeneity in the way the increased similarity between women's and men's individual observable characteristics has contributed to the improvement in female labour market performance. Indeed, while in many countries the gradual decline of the gender differences in the characteristics of the labour force is able to explain most of the observed trends, in countries traditionally characterized by a persistent male breadwinner model, the remarkable increase of female participation in the labour market must be attributed to country-specific changes in terms of policies, institutions and cultural attitudes. In Europe, cultural differences across countries are largely reflected in different welfare regimes. The following section looks in detail at the role played by the welfare regimes in shaping female labour market behaviour.

\section{Female labour market outcomes and welfare regimes}

In this section, we evaluate how the probability of participating in the labour market both over time and across welfare regimes is related to individual characteristics. We estimate a standard probit model of female labour supply on the whole sample and by welfare regime and then we interact the main determinants of participation with the trend variable in order to detect differences in trends for women with different characteristics.

\subsection{Cross country differences}

Our basic regression model specifies the labour market status as:

$$
y_{i j}^{t}=\delta \mathbf{X}_{i j}^{t}+\gamma a g e_{i j}^{t}+\lambda \text { trend }^{t}+\sigma c y c l e_{j}^{t}+c t y_{j}+\varepsilon_{i j}^{t}
$$

where $y$ is the labour market status (active) at time $t$ for individual (female) $i$ in country $j$, age is a dummy for the age group of individual $i$ (25-34; 35-44; 45-54; 55-64), cycle is a business cycle indicator (country specific and time variant), trend is a common linear trend, cty is a country dummy and $\mathbf{X}$ is a set of individual characteristics observed at time $t$. Following the existing empirical literature on women labour market participation, we include controls for the marital status, the level of education, the partner's level of education, and for family burden. In particular, besides the traditional controls for family care involvement such as the presence, the age, and the number of children, we also include a dummy for the presence in the household of an elderly person above the age of 70 as a proxy for elder care burden. As Ettner (1995) points out, although the decision to care for a senior person and the decision of fertility differ in many aspects, the influence 
of the commitment to caring for the elderly can be studied similarly to the commitment towards children ${ }^{14}$.

In order to investigate the differences in female labour market attitude across countries under different welfare regimes, we follow the Ferrera (1996) classification and divide the countries of our sample into four major groups: Southern (Spain, Italy, Greece, Portugal), Social Democratic (Sweden, Finland, Denmark), Liberal (United Kingdom), and Continental (Austria, Belgium, France, Germany, Netherlands, Ireland, Luxemburg). Table 3 presents the estimation results for the whole pooled sample (15 countries) in column 1 and for each welfare regime separately in columns $2-5^{15,16}$.

The results in Table 3 show that there are important differences across welfare regimes in the impact of individual characteristics. Being married is negatively related to women participation and employment and the effect is stronger in those countries (e.g., Continental and Southern) characterized by a more traditional family structure. Education is another important determinant of the female labour market status. As expected, a high level of education leads to more participation. Further, the educational level of the partner also has a significant impact on female participation. Finally, the age effects show the familiar hump-shaped pattern in both the participation and employment, implying an increase in the probability of participating for the age group 35-44, and then a lower probability for older groups.

Family care burdens are strongly negatively related to female labour market involvement regardless of welfare regime, though with some important differences in the magnitude of the coefficients. The presence (and the number) of young children exhibits a negative impact, and this effect is significantly stronger if children are below 4 years old. Labour market participation increases gradually when the child starts attending school and the child effect reverses only when she begins secondary school (around age 14) ${ }^{17}$. The importance of child age differs across regimes and is most critical in the UK. The age of the youngest child exerts a less detrimental effect on participation in Southern countries (which are characterized by lower participation rates for mothers) ${ }^{18}$; however, the negative effect persists even when the child is of school age. Indeed, our estimates show that the probability of participating for women with a child older than 14 (relative to women without children) is almost $4 \%$ lower in the South of Europe than in the Social Democratic countries, and 3\% lower than in Continental countries and the UK.

As for children, elderly care responsibilities are negatively related to female participation and such a relationship depends on the cultural attitude towards elderly relatives in different countries. In fact, the estimated coefficient is significantly lower in Southern countries where cohabiting with an elderly relative is a quite diffuse practice not necessarily related to the need of providing care.

Finally, the highest female participation rate is found among those aged in their late 30 s/early $40 \mathrm{~s}$ in all the welfare regimes groups, and the participation gap between oldaged women (55-64) and younger groups is significantly larger in Southern countries. This is explained both by cultural reasons (older women are of a generation in which low female labour market involvement is part of a male breadwinner system) and by early retirement pension schemes which favoured early drop outs at least until the late 1990s.

After controlling for personal characteristics and country unobserved time invariant effects, the trend indicator is positive and significant, implying that, on average, the probability of being active is $0.18 \%$ higher in 2009 than in 1994 . 
Table 3 Female activity rate by welfare regimes

\begin{tabular}{|c|c|c|c|c|c|c|c|c|c|c|c|c|c|c|c|}
\hline & \multicolumn{3}{|c|}{ All } & \multicolumn{3}{|c|}{ Liberal } & \multicolumn{3}{|c|}{ Continental } & \multicolumn{3}{|c|}{ Democratic } & \multicolumn{3}{|c|}{ Southern } \\
\hline & Coef. & & St.Err. & Coef. & & St.Err. & Coef. & & St.Err. & Coef. & & St.Err. & Coef. & & St.Err. \\
\hline \multicolumn{16}{|c|}{ Marital status } \\
\hline \multicolumn{16}{|l|}{ Single } \\
\hline Incouple & -0.071 & $* * *$ & 0.003 & -0.009 & & 0.01 & -0.098 & $* * *$ & 0.005 & -0.022 & $* * *$ & 0.005 & -0.109 & $* * *$ & 0.006 \\
\hline Separated & 0.057 & $* * *$ & 0.007 & 0.022 & & 0.018 & 0.056 & $* * *$ & 0.016 & -0.006 & & 0.024 & 0.1 & $* * *$ & 0.009 \\
\hline Divorced & 0.05 & $* * *$ & 0.004 & 0.036 & $* * *$ & 0.012 & 0.033 & $* * *$ & 0.006 & -0.013 & $*$ & 0.007 & 0.125 & $* * *$ & 0.008 \\
\hline Widowed & -0.067 & $* * *$ & 0.006 & 0.019 & & 0.013 & -0.1 & $* * *$ & 0.011 & -0.021 & $*$ & 0.013 & -0.109 & $* * *$ & 0.009 \\
\hline \multicolumn{16}{|l|}{ Children } \\
\hline \multicolumn{16}{|l|}{ No children } \\
\hline Children & -0.038 & $* * *$ & 0.003 & -0.027 & $* *$ & 0.012 & -0.036 & $* * *$ & 0.005 & -0.036 & $* * *$ & 0.006 & -0.039 & $* * *$ & 0.004 \\
\hline Child & 0.043 & $* * *$ & 0.005 & 0.064 & $* * *$ & 0.017 & 0.061 & $* * *$ & 0.008 & 0.073 & $* * *$ & 0.008 & 0.035 & $* * *$ & 0.007 \\
\hline child03 & -0.174 & $* * *$ & 0.004 & -0.275 & $* * *$ & 0.012 & -0.254 & $* * *$ & 0.007 & -0.173 & $* * *$ & 0.007 & -0.073 & $* * *$ & 0.006 \\
\hline child36 & -0.088 & $* * *$ & 0.003 & -0.177 & $* * *$ & 0.011 & -0.082 & $* * *$ & 0.006 & -0.002 & & 0.006 & -0.064 & $* * *$ & 0.005 \\
\hline child614 & -0.067 & $* * *$ & 0.003 & -0.129 & $* * *$ & 0.008 & -0.064 & $* * *$ & 0.005 & 0.027 & $* * *$ & 0.005 & -0.061 & $* * *$ & 0.004 \\
\hline \multicolumn{16}{|c|}{ Co-habiting Elderly } \\
\hline \multicolumn{16}{|l|}{ No_elderly } \\
\hline old70-80 & -0.068 & $* * *$ & 0.005 & -0.183 & $* * *$ & 0.023 & -0.149 & $* * *$ & 0.014 & -0.151 & $* * *$ & 0.016 & -0.029 & $* * *$ & 0.006 \\
\hline old80 & -0.025 & $* * *$ & 0.006 & -0.08 & $* * *$ & 0.032 & -0.036 & $* *$ & 0.017 & -0.121 & $* * *$ & 0.029 & -0.01 & & 0.008 \\
\hline \multicolumn{16}{|l|}{ Education } \\
\hline \multicolumn{16}{|l|}{ Low skilled } \\
\hline ISCED35 & 0.122 & $* * *$ & 0.002 & 0.177 & $* * *$ & 0.008 & 0.096 & $* * *$ & 0.004 & 0.091 & $* * *$ & 0.004 & 0.135 & $* * *$ & 0.003 \\
\hline ISCED67 & 0.214 & $* * *$ & 0.003 & 0.223 & $* * *$ & 0.008 & 0.176 & $* * *$ & 0.004 & 0.138 & $* * *$ & 0.005 & 0.266 & $* * *$ & 0.004 \\
\hline plSCED02 & -0.016 & $* * *$ & 0.003 & 0.035 & $* * *$ & 0.011 & 0 & & 0.007 & 0.049 & $* * *$ & 0.006 & -0.033 & $* * *$ & 0.006 \\
\hline pISCED35 & 0.039 & $* * *$ & 0.003 & 0.078 & $* * *$ & 0.009 & 0.044 & $* * *$ & 0.005 & 0.067 & $* * *$ & 0.005 & 0.017 & $* * *$ & 0.006 \\
\hline plSCED67 & 0.018 & $* * *$ & 0.004 & 0.042 & $* * *$ & 0.009 & 0.023 & $* * *$ & 0.006 & 0.058 & $* * *$ & 0.005 & 0.014 & $* *$ & 0.007 \\
\hline
\end{tabular}


Table 3 Female activity rate by welfare regimes (Continued)

\begin{tabular}{|c|c|c|c|c|c|c|c|c|c|c|c|c|c|c|c|}
\hline \multicolumn{16}{|l|}{ Age } \\
\hline \multicolumn{16}{|l|}{ age_25-34 } \\
\hline age_35-44 & 0.052 & $* * *$ & 0.003 & 0.039 & $* * *$ & 0.009 & 0.067 & $* * *$ & 0.005 & 0.074 & $* * *$ & 0.005 & 0.034 & $* * *$ & 0.005 \\
\hline age_45-54 & -0.013 & $* * *$ & 0.003 & -0.056 & $* * *$ & 0.011 & 0.018 & $* * *$ & 0.006 & 0.089 & $* * *$ & 0.005 & -0.054 & $* * *$ & 0.005 \\
\hline age_55-64 & -0.295 & $* * *$ & 0.004 & -0.3 & $* * *$ & 0.012 & -0.301 & $* * *$ & 0.007 & -0.078 & $* * *$ & 0.007 & -0.366 & $* * *$ & 0.005 \\
\hline \multicolumn{16}{|l|}{ Macro } \\
\hline Trend & 0.012 & $* * *$ & 0.001 & 0.008 & $* * *$ & 0.003 & 0.019 & $* * *$ & 0.001 & 0.004 & $* * *$ & 0.001 & 0.009 & $* * *$ & 0.001 \\
\hline Cycle & 0.003 & $* * *$ & 0.001 & 0 & & 0.002 & 0.007 & $* * *$ & 0.001 & 0.000 & & 0.001 & -0.001 & & 0.001 \\
\hline UK & Ref & & & & & & & & & & & & & & \\
\hline DK & 0.075 & $* * *$ & 0.005 & & & & & & & Ref. & & & & & \\
\hline NL & -0.039 & $* * *$ & 0.004 & & & & 0.008 & & 0.006 & & & & & & \\
\hline BE & 0.018 & $* * *$ & 0.004 & & & & 0.065 & $* * *$ & 0.005 & & & & & & \\
\hline$F R$ & 0.078 & $* * *$ & 0.004 & & & & 0.128 & $* * *$ & 0.005 & & & & & & \\
\hline IE & -0.046 & $* * *$ & 0.005 & & & & Ref. & & & & & & & & \\
\hline IT & -0.077 & $* * *$ & 0.004 & & & & & & & & & & -0.292 & $* * *$ & 0.005 \\
\hline GR & -0.041 & $* * *$ & 0.004 & & & & & & & & & & -0.263 & $* * *$ & 0.006 \\
\hline ES & 0.012 & $* * *$ & 0.004 & & & & & & & & & & -0.201 & $* * *$ & 0.006 \\
\hline PT & 0.159 & $* * *$ & 0.004 & & & & & & & & & & Ref. & & \\
\hline AT & -0.053 & $* * *$ & 0.004 & & & & 0.001 & & 0.006 & & & & & & \\
\hline $\mathrm{Fl}$ & 0.072 & $* * *$ & 0.004 & & & & & & & -0.002 & & 0.004 & & & \\
\hline SE & 0.1 & $* * *$ & 0.004 & & & & & & & 0.031 & $* * *$ & 0.004 & & & \\
\hline DE & 0.005 & & 0.004 & & & & 0.058 & $* * *$ & 0.006 & & & & & & \\
\hline LU & -0.04 & $* * *$ & 0.006 & & & & 0.008 & & 0.007 & & & & & & \\
\hline Observations & 818168 & & & 50464 & & & 328750 & & & 129536 & & & 309418 & & \\
\hline Log likelihood & -432849 & & & -26584 & & & -166126 & & & -60103 & & & -169704 & & \\
\hline pseudo - R2 & 0.148 & & & 0.123 & & & 0.142 & & & 0.086 & & & 0.174 & & \\
\hline Country dummies & yes & & & - & & & yes & & & yes & & & yes & & \\
\hline
\end{tabular}

Note: ${ }^{*}$ significant at $10 \%$; ${ }^{*}$ significant at $5 \% ;{ }^{* *}$ significant at $1 \%$. Marginal effects at the mean and clustered St.Err are reported. 


\subsection{Trends}

We then allow the impact of the determinants of female labour behaviour to vary over time by estimating the following model where the trend indicator is interacted with the individual characteristics:

$$
\begin{aligned}
y_{i j}^{t}= & \delta \mathbf{X}_{i j}^{t}+\text { rage }_{i}^{t}+\lambda \text { trend }^{t}+\text { ocycle }_{j}^{t} \\
& +\omega\left(\text { trend }^{t} \times \operatorname{age}_{i}^{t}\right)+\chi\left(\text { trend }^{t} \times \mathbf{X}_{i j}^{t}\right)+\text { cty }_{j}+\varepsilon_{i j}^{t}
\end{aligned}
$$

where trend $d^{t} \times \mathbf{X}_{i j}^{t}$ captures changes over time in the labour market status of women with certain characteristics ${ }^{19}$. Such a specification can determine whether the participation rate of women with a high level of education changed in 2007 with respect to 1994. As before, the Equation (2) is estimated on both the whole sample and each welfare regime separately. Table 4 reports the results.

Overall, the evidence shows that there are important differences in the trends of female participation, depending both on personal and family characteristics and on welfare regimes. While in the UK the positive trend is quite homogenous across women in different age groups, the increase in participation is more significant for older age groups and partly explained by cohort effects in Continental and Southern countries. Finally, in Social Democratic countries the increase in participation is significantly stronger for women in the youngest age group ${ }^{20}$. Education (own and partner's) appears to have an increasing role in stimulating female labour market involvement, with some differences across regimes. Indeed, the share of women leaving inactivity is larger among highly educated women in Continental and Social Democratic countries, while this trend is stronger for women with a low to medium level of education in Southern countries.

Over time, the labour market participation increases for women with small children. Again, such increase is not homogeneous across welfare regimes. It emerges that, between 1994 and 2009, the negative impact of young children on female labour market involvement declined significantly in Social Democratic countries and, to a lesser extent, Continental and Southern countries, while no trend has been detected for the UK. This phenomenon may be related to a larger availability of market or non- market child care services (i.e., husband's or relative's help) accompanied by a shift in people's values in all European countries (and to a larger extent in the most traditional ones) from the traditional breadwinner arrangements in favour of a more equal gender division of roles within the household. This change in the attitude towards working mothers could also have been favoured by the expansion of flexible forms of employment which facilitates the conciliation between family responsibilities and paid work.

The negative impact of informal elderly care on participation has increased over time (with the exception of Social Democratic countries). According to our results, the presence of at least one co-living elderly person has a positive (and significant) impact on female labour market involvement at the beginning of the sample period and then becomes negative. This seems to be related to the changing role of elderly relatives within the family, from providers of unpaid help within extended family models to recipients of informal long-term care in the nuclear family (Leitner 2003; Saraceno 2010; Saraceno and Naldini 2007).

In summary, the findings in Tables 3 and 4 show that the trade-off between unpaid family involvement and labour market participation has evolved in the last twenty years 
Table 4 Female activity rate: trends and welfare regimes

\begin{tabular}{|c|c|c|c|c|c|c|c|c|c|c|c|c|c|c|c|}
\hline & \multicolumn{3}{|c|}{ All } & \multicolumn{3}{|c|}{ Liberal } & \multicolumn{3}{|c|}{ Continental } & \multicolumn{3}{|c|}{ Democratic } & \multicolumn{3}{|c|}{ Southern } \\
\hline & Coef. & & St.Err. & Coef. & & St.Err. & Coef. & & St.Err. & Coef. & & St.Err. & Coef. & & St.Err. \\
\hline \multicolumn{16}{|l|}{ Marital status } \\
\hline \multicolumn{16}{|l|}{ Single } \\
\hline Incouple & -0.041 & $* *$ & 0.021 & -0.034 & & 0.073 & -0.06 & * & 0.035 & 0.023 & & 0.031 & -0.029 & & 0.032 \\
\hline Separated & 0.056 & $* * *$ & 0.007 & 0.022 & & 0.017 & 0.055 & $* * *$ & 0.017 & -0.003 & & 0.023 & 0.088 & $* * *$ & 0.009 \\
\hline Divorced & 0.049 & $* * *$ & 0.004 & 0.036 & $* * *$ & 0.013 & 0.033 & $* * *$ & 0.007 & -0.012 & * & 0.007 & 0.111 & $* * *$ & 0.008 \\
\hline Widowed & -0.067 & $* * *$ & 0.006 & 0.016 & & 0.013 & -0.094 & $* * *$ & 0.01 & -0.021 & * & 0.012 & -0.09 & $* * *$ & 0.007 \\
\hline \multicolumn{16}{|l|}{ Children } \\
\hline \multicolumn{16}{|l|}{ No children } \\
\hline Children & -0.038 & $* * *$ & 0.003 & -0.026 & $* *$ & 0.012 & -0.036 & $* * *$ & 0.005 & -0.035 & $* * *$ & 0.006 & -0.032 & $* * *$ & 0.004 \\
\hline Child & 0.052 & $* * *$ & 0.016 & 0.047 & & 0.067 & 0.133 & $* * *$ & 0.027 & 0.122 & $* * *$ & 0.026 & 0.002 & & 0.022 \\
\hline child03 & -0.16 & $* * *$ & 0.026 & -0.272 & $* * *$ & 0.092 & -0.263 & $* * *$ & 0.044 & -0.354 & $* * *$ & 0.053 & -0.064 & * & 0.034 \\
\hline child36 & -0.133 & $* * *$ & 0.024 & -0.209 & $* *$ & 0.09 & -0.201 & $* * *$ & 0.042 & 0.027 & & 0.037 & -0.11 & $* * *$ & 0.031 \\
\hline child614 & -0.046 & $* * *$ & 0.018 & -0.118 & $*$ & 0.069 & -0.047 & & 0.032 & 0.003 & & 0.033 & -0.069 & $* * *$ & 0.023 \\
\hline trend*child & -0.001 & & 0.001 & 0.001 & & 0.005 & -0.006 & $* * *$ & 0.002 & -0.004 & * & 0.002 & 0.002 & & 0.002 \\
\hline trend $^{*}$ child03 & -0.001 & & 0.002 & 0.001 & & 0.007 & 0.003 & & 0.003 & 0.011 & $* * *$ & 0.003 & 0 & & 0.003 \\
\hline trend*child36 & 0.004 & * & 0.002 & 0.003 & & 0.007 & 0.009 & $* * *$ & 0.003 & -0.002 & & 0.003 & 0.005 & $*$ & 0.002 \\
\hline trend*child614 & -0.002 & & 0.001 & 0 & & 0.005 & -0.001 & & 0.003 & 0.002 & & 0.003 & 0.001 & & 0.002 \\
\hline \multicolumn{16}{|c|}{ Co-habiting Elderly } \\
\hline \multicolumn{16}{|l|}{ No elderly } \\
\hline old7080 & 0.063 & $* *$ & 0.032 & -0.174 & & 0.179 & 0.051 & & 0.078 & -0.151 & & 0.11 & 0.059 & $*$ & 0.035 \\
\hline old80 & -0.082 & * & 0.043 & -0.025 & & 0.248 & -0.166 & & 0.119 & -0.007 & & 0.155 & -0.064 & & 0.046 \\
\hline trend*old7080 & -0.01 & $* * *$ & 0.003 & 0 & & 0.013 & -0.014 & $* *$ & 0.007 & 0 & & 0.007 & -0.007 & $* *$ & 0.003 \\
\hline trend*old80 & 0.004 & & 0.003 & -0.004 & & 0.019 & 0.01 & & 0.009 & -0.007 & & 0.012 & 0.004 & & 0.004 \\
\hline
\end{tabular}


Table 4 Female activity rate: trends and welfare regimes (Continued)

\begin{tabular}{|c|c|c|c|c|c|c|c|c|c|c|c|c|c|c|c|}
\hline \multicolumn{16}{|l|}{ Education } \\
\hline \multicolumn{16}{|l|}{ Low skilled } \\
\hline ISCED35 & 0.086 & $* * *$ & 0.016 & 0.128 & $*$ & 0.067 & 0.016 & & 0.031 & 0.082 & $* * *$ & 0.031 & 0.112 & $* * *$ & 0.021 \\
\hline ISCED67 & 0.152 & $* * *$ & 0.019 & 0.106 & & 0.074 & 0.045 & & 0.036 & 0.108 & $* * *$ & 0.033 & 0.252 & $* * *$ & 0.025 \\
\hline trend*ISCED35 & 0.003 & $* *$ & 0.001 & 0.004 & & 0.006 & 0.006 & $* * *$ & 0.002 & 0.001 & & 0.003 & 0.001 & & 0.002 \\
\hline trend*ISCED67 & 0.005 & $* * *$ & 0.002 & 0.01 & * & 0.006 & 0.011 & $* * *$ & 0.003 & 0.003 & & 0.003 & 0 & & 0.002 \\
\hline plSCED02 & -0.056 & $* *$ & 0.025 & -0.009 & & 0.099 & 0.019 & & 0.045 & 0 & & 0.044 & -0.073 & $* *$ & 0.033 \\
\hline plSCED35 & -0.058 & $* *$ & 0.024 & 0.065 & & 0.076 & 0.001 & & 0.039 & -0.015 & & 0.039 & -0.106 & $* * *$ & 0.035 \\
\hline pISCED67 & -0.064 & $* * *$ & 0.026 & 0.028 & & 0.08 & -0.059 & & 0.042 & -0.026 & & 0.043 & -0.018 & & 0.039 \\
\hline trend*pISCED02 & 0.003 & $*$ & 0.002 & 0.003 & & 0.008 & -0.001 & & 0.004 & 0.004 & & 0.004 & 0.003 & & 0.003 \\
\hline trend*pISCED35 & 0.008 & $* * *$ & 0.002 & 0.001 & & 0.006 & 0.003 & & 0.003 & 0.007 & $* *$ & 0.003 & 0.01 & $* * *$ & 0.003 \\
\hline trend*plSCED67 & 0.006 & $* * *$ & 0.002 & 0.001 & & 0.006 & 0.006 & $* *$ & 0.003 & 0.007 & $* *$ & 0.003 & 0.002 & & 0.003 \\
\hline \multicolumn{16}{|l|}{ Age } \\
\hline \multicolumn{16}{|l|}{$25-34$} \\
\hline $35-44$ & -0.042 & $* *$ & 0.021 & 0.101 & & 0.077 & -0.107 & $* * *$ & 0.039 & 0.093 & $* * *$ & 0.035 & -0.039 & & 0.027 \\
\hline $45-54$ & -0.157 & $* * *$ & 0.023 & -0.119 & & 0.091 & -0.239 & $* * *$ & 0.037 & 0.107 & $* * *$ & 0.038 & -0.139 & $* * *$ & 0.029 \\
\hline $55-64$ & -0.455 & $* * *$ & 0.02 & -0.281 & $* * *$ & 0.094 & -0.585 & $* * *$ & 0.025 & 0.005 & & 0.04 & -0.387 & $* * *$ & 0.029 \\
\hline trend*(35-44) & 0.008 & $* * *$ & 0.002 & -0.005 & & 0.006 & 0.014 & $* * *$ & 0.003 & -0.002 & & 0.003 & 0.006 & $* * *$ & 0.002 \\
\hline trend*(45-54) & 0.012 & $* * *$ & 0.002 & 0.005 & & 0.007 & 0.021 & $* * *$ & 0.003 & -0.002 & & 0.003 & 0.008 & $* * *$ & 0.002 \\
\hline trend*(55-64) $^{*}$ & 0.013 & $* * *$ & 0.002 & 0.000 & & 0.007 & 0.027 & $* * *$ & 0.003 & -0.006 & $*$ & 0.003 & 0.005 & $* *$ & 0.002 \\
\hline \multicolumn{16}{|l|}{ Macro } \\
\hline Trend & 0.000 & & 0.002 & 0.000 & & 0.008 & -0.003 & & 0.004 & 0.002 & & 0.004 & 0.002 & & 0.002 \\
\hline Cycle & 0.003 & $* * *$ & 0.001 & 0.000 & & 0.002 & 0.007 & $* * *$ & 0.001 & 0.000 & & 0.001 & -0.001 & & 0.001 \\
\hline Observations & 818168 & & & 50464 & & & 328750 & & & 129536 & & & 309418 & & \\
\hline Log likelihood & -432641.4 & & & -26576.7 & & & -165905.6 & & & -60043.2 & & & -169651 & & \\
\hline Pseudo - R2 & 0.148 & & & 0.123 & & & 0.143 & & & 0.086 & & & 0.175 & & \\
\hline Country dummies & yes & & & - & & & yes & & & yes & & & yes & & \\
\hline
\end{tabular}

Note: ${ }^{*}$ significant at $10 \% ; *{ }^{*}$ significant at $5 \% ;{ }^{* *}$ significant at $1 \%$. Marginal effects at the mean and clustered St.Err are reported. 
and such changes exhibit important country-specific patterns. Moreover, participation patterns differ substantially across age and education groups. In the following sections, we further our understanding of the relevance of institutional factors in shaping the female decisions between unpaid family responsibility and paid work.

\section{The macro policy and institutional indicators}

The previous section provides evidence that trends in female labour market participation differ significantly not only across countries with different welfare regimes but also across groups of women with different characteristics. In this section we account for such heterogeneity, by looking at the response to policy and institutional settings in terms of participation rates across groups of women. We study the role of labour market institutions and policies in explaining the observed trends by focusing on two dimensions of welfare regimes ${ }^{21}$ : (1) the social policies in support to families involved in informal care, both child-care and elderly care (hypothesis 1 in Section 2), and, (2) the policy and institutional characteristics of the labour market in terms of the degree of flexibility and security (hypothesis 2 in Section 2). Given the multilevel nature of our dataset (women nested in countries), we model female labour supply in a micro-macro design using a multi-level approach. A similar approach has been used by Ward and Dale (1992) ${ }^{22}$.

\subsection{The macro indicators}

We collect several variables related to the country-specific socioeconomic context that are expected to be important in shaping the influence of housework and family related responsibilities on female attachment to local labour markets. We distinguish six relevant dimensions of cross-countries heterogeneity: the extent of employment protection legislation, passive and active labour market policies, subsidies targeted to elderly people, subsidies targeted to families, and the extent of parental leave. Table 5 presents a description of these dimensions, by reporting on their construction and their specific components.

In order to obtain uncorrelated synthetic indicators from the six macro variables, we employ a Principal-Component Analysis (PCA) separately on the labour market institutions-related dimensions and on the more general welfare policies-related dimensions $^{23}$. In keeping with common practice (Nardo et al. (2005); Nicoletti et al. (1999); Kline (2004)), we have selected the first factor of each PCA that satisfies the following requirements: eigenvalues larger than 1 , individual contribution to the explanation of the overall variance larger than $10 \%$, cumulative contribution to the explanation of the overall variance larger than $50 \%$. Within each factor, dimensions are weighted according to the proportion of the cross-country variance explained by the factor itself. The results of the two PCA procedures are presented in Table 6.

The factor of the first PCA (Factor 1, henceforth called $P O L$ ) is highly correlated with parental leaves and family subsidies (with factor loadings larger than 0.8 ) and moderately correlated with the extent of subsidies to the elderly (factor loading approximately equal to 0.26 ). The higher the load the more relevant it is in defining the factor's dimensionality. Hence our first factor reasonably represents the generosity of national welfare regimes to households with dependent children. The factor of the second PCA (Factor 2, henceforth called $I N S T^{24}$ ) is defined by active and passive labour market policies (with factor loadings larger than 0.9 ), while the extent of employment protection legislation exerts an 
Table 5 Description of macro policy and institutional indicators

Final variable

Original variable

Description

Source

Institutions

Employment Protection Legislation

Composite indicator of employment protection which refers both to regulations concerning hiring

(e.g. rules favouring disadvantaged groups, conditions for using temporary or fixed-term contracts,

training requirements) and firing (e.g. redundancy procedures, mandated prenotification periods and

severance payments, special requirements for collective dismissals and short-time work schemes).

Passive Labour Market Policies Sum of national expenditures on active labour market policies (in percentage of national GDP) including: Out-of-work income maintenance and support, Early retirement.

Active Labour Market Policies

Sum of national expenditures on active labour market policies (in percentage of national GDP),

including: Training, Job Rotation and Job Sharing, Employment incentives, Supported employment and rehabilitation, Direct job creation, Start-up incentives.

OECD, various years

Policies

Elderly Subsidies

Sum of national transfers to the elderly population (per head at constant prices (2000) and constant PPPS

(2000), in US dollars), weighted by the percentage of old-age population (over 70 years old) within the country.

This set of policies includes: Old age cash and in kind benefits, Residential care or Home-help services.

Family Subsidies

Sum of national expenditures on allowances and other type of monthly transfers to the households

(per family at constant prices (2000) and constant PPPs(2000), in US dollars). We consider a weighted

sum of monthly family allowances for the first, second, and third child in national currency, with weights

equal to the average number of children a woman would have if she lived to the end of her childbearing

years (conventionally considered to be 15-44 but sometimes 15-49) and bore children at the prevailing

rate for each age during that period. Value of tax and benefit transfers of one-earner-two-parent two-child

families are considered. The value was calculated by subtracting the disposable income (after taxes and

transfers) of a one-earner-two-parent-two-child family from that of a comparable childless single earner.

Composite indicator of national expenditures on maternity, parental, and child care leave schemes. It is a

weighted sum of the total number of weeks of maternity, parental and child-care leave, with weights equal to the cash benefits paid during the leave as a percent of female wages in manufacturing. 
Table 6 Principal component analysis: rotated factor loadings

\begin{tabular}{lccc}
\hline Variable & Factor1 & Factor2 & Uniqueness \\
\hline Elderly Subsidies & 0.257 & & 0.9339 \\
Parental Leave & 0.8251 & & 0.3192 \\
Family Subsidies & 0.8399 & & 0.2946 \\
Employment Protection Legislation & & -0.1499 & 0.9775 \\
Passive Labour Market Policies & & 0.9119 & 0.1684 \\
Active Labour Market Policies & & 0.9215 & 0.1509 \\
\hline
\end{tabular}

inverse impact on it (with negative factor loading, -0.15). Hence, this factor resumes the degree of flexicurity of national labour market institutions $\mathrm{s}^{25}$.

\subsection{The role of policies and institutions}

Our econometric specification consists of a multi-level analysis based on our baseline probit model (1). We allow both the intercept and the impacts of some individual characteristics (namely, having small children and co-living with an old-aged dependent) to depend on the two country- specific (but time variant) macroeconomic factors defined above: INST (labour market institutional context) and $P O L$ (family oriented policies).

Our random coefficient model is composed by a first-level regression at the individual level specified as follows:

$$
y_{i j}^{t}=\beta_{0 j}^{t}+\beta_{11 j}^{t} C H I L D_{i j}^{t}+\beta_{12 j}^{t} E L D E R L Y_{i j}^{t}+\beta_{2} \mathbf{x}_{2 i j}^{t}+\varepsilon_{i j}^{t}
$$

and a second level set of regressions as follows:

$$
\begin{aligned}
& \beta_{0 j}^{t}=\delta_{0}+\delta_{1} I N S T_{j}^{t}+\delta_{2} P O L_{j}^{t}+v_{j}^{t} \\
& \beta_{11 j}^{t}=\gamma_{10}+\gamma_{11} I N S T_{j}^{t}+\gamma_{12} P O L_{j}^{t}+v_{1 j}^{t} \\
& \beta_{12 j}^{t}=\gamma_{20}+\gamma_{21} I N S T_{j}^{t}+\gamma_{22} P O L_{j}^{t}+v_{2 j}^{t}
\end{aligned}
$$

where $\mathbf{x}_{2}$ is a set of additional controls which capture the impact of other microcharacteristics on the likelihood of female participation.

We implement Generalized Linear Latent Models to estimate a two-level RandomIntercept Probit model and a two-level Random-Coefficient Probit model, taking into account the nesting of individuals in their country of origin ${ }^{26}$. Unlike in the analysis performed in Section 4, we now focus on women in prime-age group (25-54) because family care burdens, such as child care and elderly care, are less relevant to those in the elder group (55-64) ${ }^{27}$. The model is estimated for the whole sample (pooled model) and then for each age group separately. We also test whether and to what extent changes in family policies and labour market institutions affect differently the labour market decisions of women with different levels of education and estimate model (3) for the three education groups (primary, secondary and tertiary education) ${ }^{28}$.

The results are reported in Table 7 for the whole sample and in Table 8 for the three age groups (Panel A) and the three education groups (Panel B) ${ }^{29}$. 
Table 7 Two-level probit regression: the impact policy \& institutions - whole sample

\begin{tabular}{lcrr} 
& All & \\
\cline { 2 - 4 } & Coef. & St.Err. \\
\hline INST & -0.006 & $* * 014$ \\
POL & 0.003 & $* * *$ & 0.024 \\
INST $\times$ child06 & 0.015 & $* * *$ & 0.001 \\
POL $\times$ child06 & 0 & $* *$ & 0.001 \\
INST $\times$ old70 & -0.02 & & 0.003 \\
POL $\times$ old70 & -0.008 & & 0.003 \\
\hline VPC_overall & 0.056 & & \\
VPC_level 2 & 0.426 &
\end{tabular}

Both the POL and INST indicators exert are significantly related to female likelihood of being active, though their effect is mediated by the type of unpaid work involvement (presence of child and/or elder person) and differs substantially across age and education groups.

Regarding the role of family policies $(P O L)$, the availability of childcare subsidies and child-friendly policies is positively related to the activity rate of women with children and the effect is significant for young women (25-34) at the early stage of their work life and, quite surprisingly, for medium and high educated women. Indeed the estimated coefficient is not significant for low-skilled women, whose employment opportunities are limited both in terms of job quality and wages ${ }^{30}$.

Conversely, policy measures to help women combine caring and job responsibilities have varying effects on the willingness to work of women co-living with an elderly person. The coefficient is in general negative and significant for older (age group 44-55) and low educated women. These results show that the effect of policies on female choice between paid work and unpaid care crucially depends on their outside family options and labour market potential outcomes. In general, cash benefits increase household income and the reservation wage at which women are available to work. Therefore, more generous supports for child-related and elder-related costs are more likely to discourage the labour market participation of low-skilled women in charge of family care, since their labour market options (in terms of wage and type of jobs) are poorer.

Turning to the effects of the institutions indicator (INST), more flexibility and/or more security is employment-enhancing for young women (25-34) with small children regardless the level of education. These results imply that the availability of flexicure jobs favours the labour market participation of women with children - especially those women at the beginning of their working career -, by reducing the labour market entry costs. Women with elderly care responsibility respond differently to changes in the labour market institutional framework. Higher labour flexibility seems to be detrimental for the labour market involvement of women co-living with an elderly person. This is apparently in contrast with the existing empirical evidence which shows that less educated women (with a lower attachment to work) are more responsive to work incentives created by policy/institutional changes. The result may be related to the fact that only a few countries in Europe have combined the two dimensions of flexibility and security ${ }^{31}$, and, in most cases, deregulation is moving forward without sufficient social compensation. In this respect, the growing availability of flexible (low-paid) jobs, which very often represent 
Table 8 Two-level probit regression: the impact policy \& institutions by age (Panel A) and education (Panel B)

\begin{tabular}{|c|c|c|c|c|c|c|c|c|c|c|c|c|c|c|c|c|c|c|}
\hline & \multicolumn{9}{|c|}{ Panel A } & \multicolumn{9}{|c|}{ Panel B } \\
\hline & \multicolumn{3}{|c|}{$25-34$} & \multicolumn{3}{|c|}{$35-44$} & \multicolumn{3}{|c|}{$45-54$} & \multicolumn{3}{|c|}{ ISCED 0-2 } & \multicolumn{3}{|c|}{ ISCED 3-5 } & \multicolumn{3}{|c|}{ ISCED 6-7 } \\
\hline & Coef. & & St.Err. & Coef. & & St.Err. & Coef. & & St.Err. & Coef. & & St.Err. & Coef. & & St.Err. & Coef. & & St.Err. \\
\hline$\overline{\text { INST }}$ & -0.031 & & 0.037 & 0.008 & & 0.015 & 0.024 & & 0.015 & 0.004 & & 0.028 & -0.012 & & 0.013 & -0.015 & $* * *$ & 0.014 \\
\hline POL & -0.009 & & 0.045 & 0.013 & & 0.026 & 0.006 & & 0.02 & -0.021 & & 0.041 & -0.001 & & 0.024 & -0.01 & & 0.02 \\
\hline INST $\times$ child06 & 0.04 & $* * *$ & 0.002 & 0.002 & & 0.002 & 0.008 & & 0.006 & 0.012 & $* * *$ & 0.003 & 0.014 & $* * *$ & 0.002 & 0.025 & $* * *$ & 0.002 \\
\hline POL $\times$ child06 & 0.006 & $* * *$ & 0.002 & 0.003 & & 0.002 & 0.008 & & 0.006 & 0.001 & & 0.002 & 0.004 & $* *$ & 0.002 & 0.011 & $* * *$ & 0.002 \\
\hline INST $\times$ old70 & -0.013 & $* *$ & 0.006 & -0.019 & $* * *$ & 0.005 & -0.023 & $* * *$ & 0.005 & -0.041 & $* * *$ & 0.006 & -0.02 & $* * *$ & 0.006 & -0.001 & & 0.006 \\
\hline POL $\times$ old70 & -0.008 & & 0.007 & 0.004 & & 0.006 & -0.026 & $* * *$ & 0.005 & -0.02 & $* * *$ & 0.006 & -0.001 & & 0.006 & 0.002 & & 0.006 \\
\hline$\overline{\text { VPC_overall }}$ & 0.199 & & & 0.063 & & & 0.042 & & & 0.121 & & & 0.048 & & & 0.058 & & \\
\hline VPC_level 2 & 0.675 & & & 0.439 & & & 0.439 & & & 0.572 & & & 0.419 & & & 0.453 & & \\
\hline
\end{tabular}

Note: ${ }^{*}$ significant at $10 \% ;{ }^{* *}$ significant at $5 \% ;{ }^{* * *}$ significant at $1 \%$. Marginal effects at the mean and clustered St.Err are reported. 
a forced alternative rather than an option for more stable forms of employment, makes unpaid elderly caring more attractive than paid occupations, especially in countries where family caring activities are supported by monetary allowances that can be freely used to complement the family budget ${ }^{32}$. This is confirmed by the fact that the negative role of flexibility on the labour market inclusion of women with elder-care responsibilities holds especially for low to medium-educated women whose work opportunities are in general poorer.

To summarize, female labour market behaviour is significantly associated with the institutional characteristics of the labour market and the social policy environment, though this link is mediated by individual characteristics. In particular, social policies aimed at women involved in family care have a strong and significant role on the labour market participation of young mothers with a medium to high level of education. The effect is nevertheless negative when older and low skilled women are involved in elderly care. Conversely, more flexicure institutions significantly enhance the participation of mothers at early stage of their working career who benefit more of a larger availability of flexible forms of employment and a reduction of the labour market entry costs. The same result does not hold for low-skilled women with elder-care responsibilities.

Our results indicate that social policies and labour market institutional characteristics explain a non-negligible percentage of the female labour market participation across European countries. The variance partition coefficient (VPC) for the overall model (Table 7 ) is approximately equal to 0.06 , which indicates that $6 \%$ of the observed variability in the participation rates can be attributed to country-level factors. This coefficient increases when the model is separately estimated by age-group and educational level (Table 8). In particular, macroeconomic heterogeneity is particularly relevant in explaining cross-country differences in the participation rates of younger and less skilled women (VPC increases up to $20 \%$ and $11 \%$ respectively), while more than $95 \%$ of the observed variability in the labour market participation of women between 45 and 55 years old is due to individual characteristics. The macro factors INST and POL explain up to 67\% of the overall cross-countries variance, as shown by the level-2 variance partition coefficients. Thus the remaining 33\% is due to unobserved country-level characteristics, such as changes in cultural attitude towards female labour market involvement, as well as other country-specific time-variant factors which have not been explicitly considered in the model.

\subsection{The role of flexicurity}

In the last set of regressions we focus more specifically on the impact of flexicurity on women labour market involvement by disentangling the impact of the two components of the indicator INST - flexibility (FLEX) and security $(S E C)$ and their interaction (FLEX $\times$ $S E C)^{33}$.

The results for the pooled sample are reported in Table 9; those for the three age groups and for the different levels of education are reported in Table 10, Panel A and B respectively.

Table 9 shows that a higher degree of labour flexibility has a positive effect on the activity rate only if it is accompanied by policies which are aimed at guaranteeing access to employment security in terms of both active labour market policies and the 


\begin{tabular}{lccr}
\hline & \multicolumn{2}{c}{ All } \\
\cline { 2 - 4 } & Coef. & $* *$ & St.Err. \\
\hline FLEX & -0.248 & $*$ & 0.118 \\
SEC & -0.209 & $*$ & 0.116 \\
FLEX x SEC & 0.118 & $* * *$ & 0.061 \\
FLEX x child06 & -0.057 & $* * *$ & 0.003 \\
SEC x child06 & -0.022 & $* * *$ & 0.004 \\
FLEX x SEC x child06 & 0.025 & $* * *$ & 0.002 \\
FLEX x old70 & -0.022 & $* * *$ & 0.005 \\
SEC x old70 & -0.031 & & 0.008 \\
FLEX x SEC x old70 & 0.006 & & 0.005 \\
\hline VPC_overall & 0.224 & & \\
VPC_level 2 & 0.264 & & \\
\hline
\end{tabular}

inclusiveness of unemployment benefits. At the same time, a larger degree of security is beneficial to female involvement only in sufficiently flexible labour markets, which provide an easier access to employment. The impacts of flexibility, security and their interactions are significant and qualitatively the same across age groups with the exception of those in the oldest age group (44-54 in our sample). The interaction between flexibility and security is stronger for young women at the early stage of their working career and, consistently with the results found in the previous set of regressions, for those women with family care responsibilities. These results suggest that combining a high degree of labour market flexibility with a high level of social protection leads to significant gains in terms of female labour market participation, while omitting one of the two aspects can produce sub-optimal (or even negative) outcomes in terms of labour market performance. The marginal effect of flexibility on female activity rate becomes positive in correspondence to a value of the security indicator above 2.00, the level of security of countries such as Sweden and France in our sam$\mathrm{ple}^{34}$. On the other hand, the marginal effect of security becomes positive for value of the flexibility indicator above 1.76, the amount of flexibility in Germany, Finland and Netherlands ${ }^{35}$.

In Figure 5 we can observe that in the period 2004-2009, the countries for which both the flexibility and security indicators are above the estimated thresholds are the Social Democratic countries (though Sweden only marginally), Netherlands and at the margin Belgium, and Germany ${ }^{36}$. After the institutional reforms implemented in the late 1990s and early 2000s to promote a more flexible labour market, Italy appears still deficient on the security side. The opposite holds for France and Spain which are still characterized by a rigid labour market. Greece and Portugal remain well below both the thresholds.

The picture that emerges from this last exercise can be summarized by saying that in the Social Democratic and some Central European countries, institutional changes towards the flexicurity model are correlated with positive trends in female labour market participation and this is particular true for young women with kids. On the contrary, in southern European countries and the UK, the adopted mix of security and flexibility is not enough to stimulate female involvement in the labour market. 
Table 10 Two-level probit regression flexicurity: the impact of flexicurity by age (Panel A) and education (Panel B)

\begin{tabular}{|c|c|c|c|c|c|c|c|c|c|c|c|c|c|c|c|c|c|c|}
\hline & \multicolumn{9}{|c|}{ Panel A } & \multicolumn{9}{|c|}{ Panel B } \\
\hline & \multicolumn{3}{|c|}{$25-34$} & \multicolumn{3}{|c|}{$35-44$} & \multicolumn{3}{|c|}{$45-54$} & \multicolumn{3}{|c|}{ ISCED 0-2 } & \multicolumn{3}{|c|}{ ISCED 3-5 } & \multicolumn{3}{|c|}{ ISCED 6-7 } \\
\hline & Coef. & & St.Err. & Coef. & & St.Err. & Coef. & & St.Err. & Coef. & & St.Err. & Coef. & & St.Err. & Coef. & & St.Err. \\
\hline FLEX & -0.197 & & 0.139 & -0.131 & & 0.094 & -0.057 & & 0.072 & -0.136 & & 0.149 & -0.002 & & 0.064 & -0.014 & & 0.046 \\
\hline SEC & -0.168 & * & 0.098 & -0.132 & & 0.097 & -0.044 & & 0.07 & -0.242 & * & 0.149 & 0.022 & & 0.063 & -0.007 & & 0.049 \\
\hline FLEX $\times$ SEC & 0.095 & * & 0.05 & 0.084 & * & 0.044 & 0.029 & & 0.033 & 0.133 & $* * *$ & 0.054 & 0.026 & & 0.032 & 0.022 & & 0.025 \\
\hline FLEX $\times$ child06 & -0.056 & $* * *$ & 0.004 & -0.069 & $* * *$ & 0.004 & -0.044 & $* * *$ & 0.011 & -0.067 & $* * *$ & 0.005 & -0.084 & $* * *$ & 0.005 & -0.052 & $* * *$ & 0.004 \\
\hline SEC $\times$ child06 & 0.021 & $* * *$ & 0.006 & -0.067 & $* * *$ & 0.007 & -0.022 & & 0.019 & -0.01 & & 0.008 & -0.048 & $* * *$ & 0.006 & 0.014 & $* *$ & 0.006 \\
\hline FLEX $\times$ SEC $\times$ child06 & 0.019 & $* * *$ & 0.003 & 0.038 & $* * *$ & 0.003 & 0.016 & * & 0.009 & 0.019 & $* * *$ & 0.004 & 0.038 & $* * *$ & 0.003 & 0.006 & $*$ & 0.003 \\
\hline FLEX $\times$ old70 & -0.027 & ** & 0.011 & -0.033 & $* * *$ & 0.009 & -0.01 & & 0.008 & -0.002 & & 0.009 & -0.048 & $* * *$ & 0.01 & -0.013 & & 0.009 \\
\hline SEC $\times$ old70 & -0.042 & $* * *$ & 0.016 & -0.036 & $* * *$ & 0.013 & -0.017 & & 0.012 & -0.013 & & 0.013 & -0.078 & $* * *$ & 0.014 & -0.009 & & 0.014 \\
\hline FLEX $\times$ SEC $\times$ old70 & 0.022 & $* *$ & 0.01 & 0.01 & & 0.008 & -0.007 & & 0.007 & 0.017 & $* *$ & 0.008 & 0.035 & $* * *$ & 0.008 & 0.005 & & 0.009 \\
\hline VPC_overall & 0.257 & & & 0.308 & & & 0.333 & & & 0.365 & & & 0.211 & & & 0.211 & & \\
\hline VPC_level 2 & 0.287 & & & 0.385 & & & 0.589 & & & 0.418 & & & 0.322 & & & 0.323 & & \\
\hline
\end{tabular}

Note: ${ }^{*}$ significant at $10 \% ;{ }^{*}$ significant at $5 \%$; ${ }^{* *}$ significant at $1 \%$. Marginal effects at the mean and clustered St.Err are reported. 


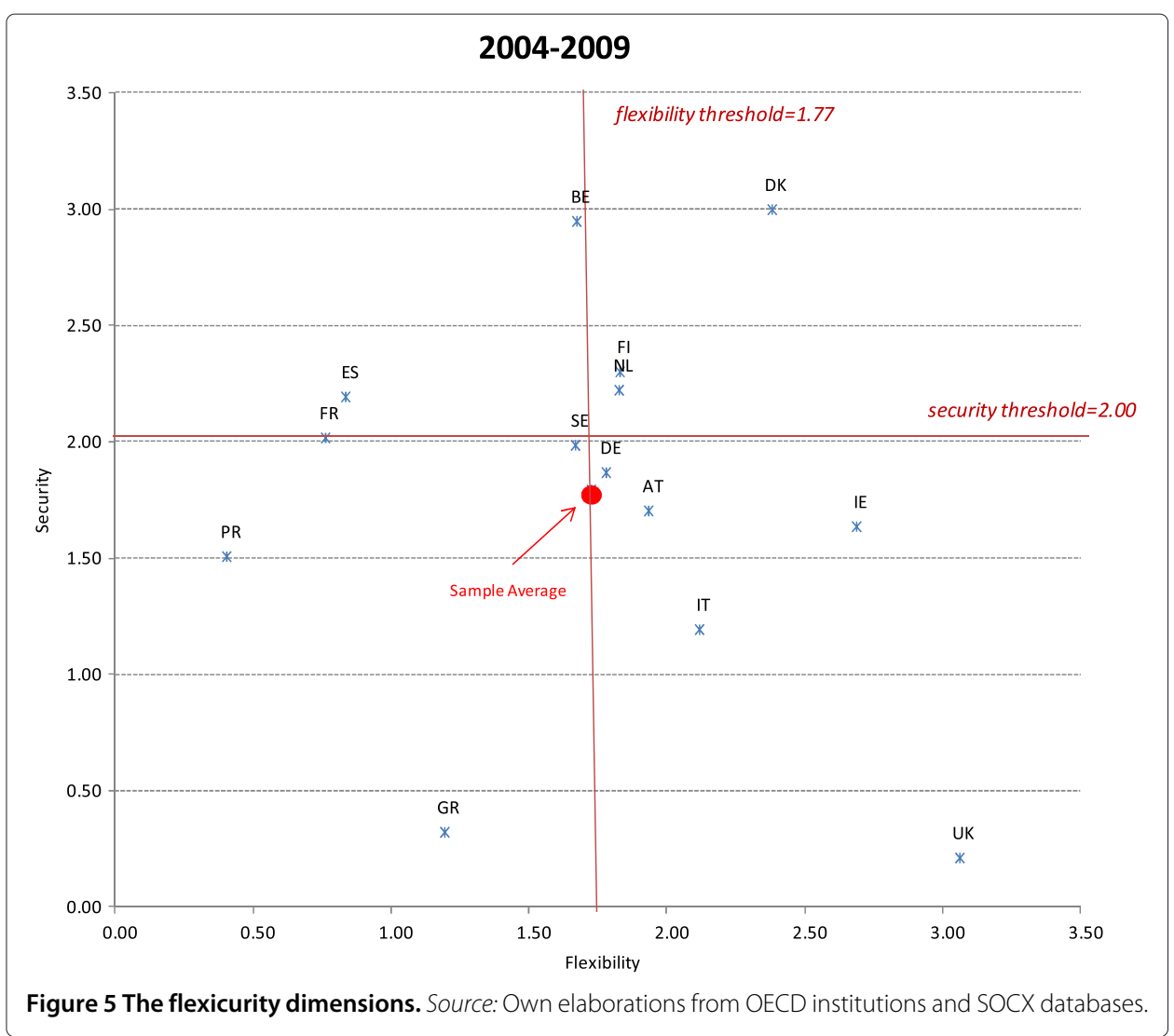

\subsection{Quantifying the influence of institutions and social policies}

We now provide a more precise quantification of the effects of labour market flexibility and security and of those of social policies in support to families on women' activity rate. Following the growth accounting methodology proposed by Stoker (1985), it is possible to show that, under plausible restrictions, a first-order difference of our multilevel model provides an Oaxaca-fashion decomposition of changes in female activity rates. Such a decomposition enables us to assess how much of the observed growth in female labour force participation is due to changes in the macro factors (INST and POL), as opposed to changes from other sources (such as changes in the individual characteristics). More specifically, the variation of the female activity rate between two periods is composed of five different elements. The first term describes how much of the change in women participation rate comes exclusively from changes in individual characteristics. The second term quantifies how much of that change is due to the interplay between individual characteristics and country-specific unobserved heterogeneity. The third term captures the effects arising from the interaction between changes in individual characteristics and observed macro factors, whereas the fourth component captures the influence of changes in the macro factors INST and POL. The fifth term is a residual component. The technical details of this decomposition are reported in Appendix B.

Table 11 collects the estimation results which are obtained using the decomposition for the whole sample, whereas Table 12 shows the evidence for the four welfare regimes separately. 
Table 11 INST and POL contribution to female participation

\begin{tabular}{|c|c|c|c|c|}
\hline & \multicolumn{4}{|c|}{ EU15 } \\
\hline & $\begin{array}{l}\Delta \text { Activity } \\
\text { rate }\end{array}$ & $\begin{array}{l}\text { Predicted by } \\
\text { INST and POL }\end{array}$ & $\begin{array}{l}\text { Predicted by } \\
\text { other observables }\end{array}$ & $\begin{array}{l}\text { INST and POL } \\
\text { contribution (\%) }\end{array}$ \\
\hline 1995 & 0.0053 & 0.0009 & 0.0007 & 0.17 \\
\hline 1996 & 0.0165 & 0.0005 & 0.0087 & 0.03 \\
\hline 1997 & 0.0234 & 0.0011 & 0.0183 & 0.047 \\
\hline 1998 & 0.0318 & 0.0025 & 0.0123 & 0.079 \\
\hline 1999 & 0.0439 & 0.0027 & 0.013 & 0.062 \\
\hline 2000 & 0.0515 & 0.0037 & 0.0097 & 0.072 \\
\hline 2004 & 0.0813 & 0.0021 & 0.0558 & 0.026 \\
\hline 2005 & 0.0888 & 0.0046 & 0.0605 & 0.052 \\
\hline 2006 & 0.097 & 0.0055 & 0.0626 & 0.057 \\
\hline 2007 & 0.1023 & 0.007 & 0.064 & 0.068 \\
\hline 2008 & 0.1073 & 0.0075 & 0.0614 & 0.07 \\
\hline 2009 & 0.113 & 0.0026 & 0.0557 & 0.023 \\
\hline Mean & & & & 0.063 \\
\hline
\end{tabular}

On average, 6.2\% of the overall increase in female participation between 1994 and 2009 is associated with changes in the institution and policy indicators. Only a small part of the actual rise over time in the employment rate is associated with changes in the institutions and policies indicators in Southern countries (around 3\%), while the contribution is remarkable higher in the Social Democratic countries. For these countries, the INST and $P O L$ indicators predict more than $14 \%$ of the observed change in the female participation. This last result aligns with the findings discussed in the previous session, which show that in the Social Democratic regime, institutional changes towards the flexicurity model are highly correlated with positive trends in female labour market participation.

Table 13 and Table 14 present the estimation results for the three age and the three education groups respectively.

These results indicate that the contribution of changes of institutions and policies to the growth of female participation is considerably higher for young $(24.6 \%)$ and high skilled women (38.6\%). In line with the previous literature, these findings confirm that the social welfare changes and the labour market regulatory reforms in Europe contribute to explain the observed trends in the activity rate of women who face higher labour market entry costs, such as young women who are at the beginning of their working career and more involved in child care duties. Interestingly, the mix of labour market reforms and policies changes which have been implemented in Europe in the last 20 years fail to explain the observed pattern of the activity rate of low-educated women.

\section{Conclusions}

This paper provides detailed macro-level evidence on female labour market participation trends in the last 20 years for a large set of EU countries using micro data from the ECHP and EU-SILC surveys. Three main results emerge from our analysis.

First, we show that the observed trends in the labour market participation of women have not been uniform across countries in different welfare regimes and, within countries, across women with different individual and family characteristics. For example, according to our results, the labour market involvement of women with young children has 
Table 12 INST and POL contribution to female participation by welfare regime

\begin{tabular}{|c|c|c|c|c|c|c|c|c|}
\hline & $\begin{array}{c}\Delta \text { Activity } \\
\text { rate }\end{array}$ & $\begin{array}{l}\text { Predicted by } \\
\text { INST and POL }\end{array}$ & $\begin{array}{c}\text { Predicted by } \\
\text { other observables }\end{array}$ & $\begin{array}{c}\text { INST and POL } \\
\text { contribution (\%) }\end{array}$ & $\begin{array}{c}\Delta \text { Activity } \\
\text { rate }\end{array}$ & $\begin{array}{l}\text { Predicted by } \\
\text { INST and POL }\end{array}$ & $\begin{array}{c}\text { Predicted by } \\
\text { other observables }\end{array}$ & $\begin{array}{l}\text { INST and POL } \\
\text { contribution (\%) }\end{array}$ \\
\hline & \multicolumn{4}{|c|}{ Continental } & \multicolumn{4}{|c|}{ Social democratic } \\
\hline 1995 & 0.0059 & 0.0008 & -0.0036 & 0.136 & -0.001 & 0.0007 & -0.0064 & -0.7 \\
\hline 1996 & 0.0186 & 0.0001 & -0.0029 & 0.005 & -0.001 & -0.0002 & -0.0198 & 0.2 \\
\hline 1997 & 0.0307 & 0.0007 & -0.0011 & 0.023 & -0.0083 & 0.0014 & -0.0192 & -0.169 \\
\hline 1998 & 0.0407 & 0.0032 & -0.025 & 0.079 & -0.0067 & 0.0021 & -0.0184 & -0.313 \\
\hline 1999 & 0.0566 & 0.004 & -0.0263 & 0.071 & -0.0007 & 0.0002 & -0.0175 & -0.271 \\
\hline 2000 & 0.0651 & 0.0051 & -0.031 & 0.078 & -0.0003 & 0.00017 & -0.015 & -0.567 \\
\hline 2004 & 0.0996 & -0.0003 & 0.0279 & -0.003 & 0.0003 & 0.00023 & 0.0016 & 0.767 \\
\hline 2005 & 0.109 & 0.0058 & 0.0429 & 0.053 & 0.0053 & 0.0045 & 0.0002 & 0.849 \\
\hline 2006 & 0.1181 & 0.0064 & 0.0439 & 0.054 & 0.0083 & 0.0053 & 0.0009 & 0.639 \\
\hline 2007 & 0.126 & 0.0074 & 0.0454 & 0.059 & 0.0117 & 0.0075 & -0.0008 & 0.641 \\
\hline 2008 & 0.1281 & 0.0098 & 0.0413 & 0.077 & 0.018 & 0.0079 & -0.0046 & 0.439 \\
\hline 2009 & 0.1357 & 0.0027 & 0.0319 & 0.02 & 0.016 & 0.0031 & -0.0091 & 0.194 \\
\hline \multirow[t]{2}{*}{ Mean } & & & & 0.054 & & & & 0.142 \\
\hline & \multicolumn{4}{|c|}{ Liberal } & \multicolumn{4}{|c|}{ Southern } \\
\hline 1995 & 0.002 & -0.0002 & 0.0017 & -0.1 & 0.0097 & 0.0009 & 0.0031 & 0.093 \\
\hline 1996 & 0.007 & 0.0002 & 0.0038 & 0.029 & 0.0283 & 0.0014 & 0.004 & 0.049 \\
\hline 1997 & 0.011 & 0.0003 & 0.0059 & 0.027 & 0.0375 & 0.002 & 0.0057 & 0.053 \\
\hline 1998 & 0.013 & 0.0006 & 0.0534 & 0.046 & 0.0498 & 0.0025 & 0.0082 & 0.05 \\
\hline 1999 & 0.021 & 0.0009 & 0.0585 & 0.043 & 0.0607 & 0.0019 & 0.01 & 0.031 \\
\hline 2000 & 0.023 & 0.0022 & 0.0395 & 0.096 & 0.0735 & 0.0018 & 0.0125 & 0.024 \\
\hline 2004 & & & & & 0.1235 & 0.0013 & 0.0499 & 0.011 \\
\hline 2005 & 0.034 & 0.004 & 0.0739 & 0.118 & 0.1298 & 0.002 & 0.0514 & 0.015 \\
\hline 2006 & 0.037 & 0.0038 & 0.0708 & 0.103 & 0.1415 & 0.0032 & 0.0547 & 0.023 \\
\hline 2007 & 0.037 & 0.004 & 0.0774 & 0.108 & 0.145 & 0.0049 & 0.0563 & 0.034 \\
\hline 2008 & 0.043 & 0.0035 & 0.0764 & 0.081 & 0.1537 & 0.0038 & 0.0552 & 0.025 \\
\hline 2009 & & & & & 0.1622 & -0.0006 & 0.0562 & -0.004 \\
\hline Mean & & & & 0.055 & & & & 0.034 \\
\hline
\end{tabular}


Table 13 INST and POL contribution to female participation by age groups

\begin{tabular}{|c|c|c|c|c|c|c|c|c|c|c|c|c|}
\hline & \multicolumn{4}{|c|}{$25-34$} & \multicolumn{4}{|c|}{$35-44$} & \multicolumn{4}{|c|}{$45-54$} \\
\hline & $\begin{array}{c}\Delta \text { Activity } \\
\text { rate }\end{array}$ & $\begin{array}{l}\text { Predicted by } \\
\text { INST and } \\
\text { POL }\end{array}$ & $\begin{array}{c}\text { Predicted by } \\
\text { other } \\
\text { observables }\end{array}$ & $\begin{array}{l}\text { INST and POL } \\
\text { contribution (\%) }\end{array}$ & $\begin{array}{l}\Delta \text { Activity } \\
\text { rate }\end{array}$ & $\begin{array}{l}\text { Predicted by } \\
\text { INST and } \\
\text { POL }\end{array}$ & $\begin{array}{c}\text { Predicted by } \\
\text { other } \\
\text { observables }\end{array}$ & $\begin{array}{l}\text { INST and POL } \\
\text { contribution (\%) }\end{array}$ & $\begin{array}{l}\Delta \text { Activity } \\
\text { rate }\end{array}$ & $\begin{array}{l}\text { Predicted by } \\
\text { INST and } \\
\text { POL }\end{array}$ & $\begin{array}{c}\text { Predicted by } \\
\text { other } \\
\text { observables }\end{array}$ & $\begin{array}{l}\text { INST and POL } \\
\text { contribution (\%) }\end{array}$ \\
\hline 1995 & 0.016 & 0.0073 & -0.0028 & 0.456 & 0.0346 & 0.0003 & -0.003 & 0.009 & 0.0556 & -0.0031 & 0.0089 & -0.056 \\
\hline 1996 & 0.029 & 0.0032 & -0.0022 & 0.11 & 0.0473 & 0.0013 & 0.0026 & 0.027 & 0.0609 & 0.0012 & 0.0276 & 0.02 \\
\hline 1997 & 0.0342 & 0.0043 & -0.0074 & 0.126 & 0.0549 & 0.0022 & 0.0098 & 0.04 & 0.0728 & 0.0024 & 0.0535 & 0.033 \\
\hline 1998 & 0.038 & 0.0088 & -0.0172 & 0.232 & 0.058 & 0.0045 & 0.0003 & 0.078 & 0.0876 & 0.0007 & 0.0536 & 0.008 \\
\hline 1999 & 0.0509 & 0.0108 & -0.0209 & 0.212 & 0.0713 & 0.0048 & -0.0021 & 0.067 & 0.1049 & 0.0004 & 0.0629 & 0.004 \\
\hline 2000 & 0.0598 & 0.0191 & -0.0331 & 0.319 & 0.0796 & 0.0045 & -0.0063 & 0.057 & 0.1121 & -0.004 & 0.0675 & -0.036 \\
\hline 2004 & 0.0741 & 0.0159 & 0.0314 & 0.215 & 0.1044 & 0.0006 & 0.0523 & 0.006 & 0.1614 & -0.0031 & 0.1078 & -0.019 \\
\hline 2005 & 0.0769 & 0.0195 & 0.0019 & 0.254 & 0.111 & 0.0068 & 0.0509 & 0.061 & 0.1772 & -0.0015 & 0.1415 & -0.008 \\
\hline 2006 & 0.0842 & 0.0229 & -0.0041 & 0.272 & 0.1194 & 0.0077 & 0.0518 & 0.064 & 0.1871 & -0.0033 & 0.1536 & -0.018 \\
\hline 2007 & 0.0856 & 0.0289 & -0.0098 & 0.338 & 0.1257 & 0.0094 & 0.0523 & 0.075 & 0.1962 & -0.006 & 0.1638 & -0.031 \\
\hline 2008 & 0.0887 & 0.0291 & -0.0176 & 0.328 & 0.1285 & 0.0104 & 0.0493 & 0.081 & 0.2061 & -0.0057 & 0.1657 & -0.028 \\
\hline 2009 & 0.0949 & 0.0087 & -0.0207 & 0.092 & 0.1359 & 0.0038 & 0.0423 & 0.028 & 0.2107 & 0.0005 & 0.1598 & 0.002 \\
\hline Mean & & & & 0.246 & & & & 0.049 & & & & -0.011 \\
\hline
\end{tabular}


Table 14 INST and POL contribution to female participation by education groups

\begin{tabular}{|c|c|c|c|c|c|c|c|c|c|c|c|c|}
\hline & \multicolumn{4}{|c|}{ ISCED 0-2 } & \multicolumn{4}{|c|}{ ISCED 3-5 } & \multicolumn{4}{|c|}{ ISCED 6-7 } \\
\hline & $\begin{array}{l}\Delta \text { Activity } \\
\text { rate }\end{array}$ & $\begin{array}{l}\text { Predicted by } \\
\text { INST and } \\
\text { POL }\end{array}$ & $\begin{array}{l}\text { Predicted by } \\
\text { other } \\
\text { observables }\end{array}$ & $\begin{array}{l}\text { INST and POL } \\
\text { contribution (\%) }\end{array}$ & $\begin{array}{l}\Delta \text { Activity } \\
\text { rate }\end{array}$ & $\begin{array}{l}\text { Predicted by } \\
\text { INST and } \\
\text { POL }\end{array}$ & $\begin{array}{l}\text { Predicted by } \\
\text { other } \\
\text { observables }\end{array}$ & $\begin{array}{l}\text { INST and POL } \\
\text { contribution (\%) }\end{array}$ & $\begin{array}{l}\Delta \text { Activity } \\
\text { rate }\end{array}$ & $\begin{array}{l}\text { Predicted by } \\
\text { INST and } \\
\text { POL }\end{array}$ & $\begin{array}{l}\text { Predicted by } \\
\text { other } \\
\text { observables }\end{array}$ & $\begin{array}{l}\text { INST and POL } \\
\text { contribution (\%) }\end{array}$ \\
\hline 1995 & 0.0485 & -0.0017 & -0.0002 & -0.035 & 0.0163 & 0.0023 & -0.0001 & 0.141 & 0.0117 & 0.0054 & -0.0038 & 0.462 \\
\hline 1996 & 0.0401 & -0.0021 & 0.0034 & -0.052 & 0.0301 & 0.0005 & 0.0055 & 0.017 & 0.0163 & -0.0028 & -0.0006 & -0.172 \\
\hline 1997 & 0.0467 & -0.0034 & 0.0106 & -0.073 & 0.0297 & 0.0005 & 0.0165 & 0.017 & 0.0191 & -0.0015 & 0.0021 & -0.079 \\
\hline 1998 & 0.0694 & -0.0131 & 0.0046 & -0.189 & 0.0513 & 0.0034 & 0.0152 & 0.066 & 0.0339 & 0.0104 & -0.0164 & 0.307 \\
\hline 1999 & 0.0608 & -0.0115 & 0.0044 & -0.189 & 0.0491 & 0.0035 & 0.0154 & 0.071 & 0.0301 & 0.0119 & -0.0199 & 0.395 \\
\hline 2000 & 0.0677 & -0.0143 & 0.0034 & -0.211 & 0.0574 & 0.0067 & 0.0154 & 0.117 & 0.0293 & 0.02 & -0.0226 & 0.683 \\
\hline 2004 & 0.0825 & -0.0061 & 0.0435 & -0.074 & 0.0656 & 0.0063 & 0.0383 & 0.096 & 0.0336 & 0.0157 & -0.0012 & 0.467 \\
\hline 2005 & 0.0866 & -0.0115 & 0.0387 & -0.133 & 0.0697 & 0.0061 & 0.0254 & 0.088 & 0.0361 & 0.0177 & -0.0169 & 0.49 \\
\hline 2006 & 0.0923 & -0.0132 & 0.04 & -0.143 & 0.0791 & 0.0071 & 0.0276 & 0.09 & 0.0388 & 0.0207 & -0.0173 & 0.534 \\
\hline 2007 & 0.1008 & -0.0168 & 0.0402 & -0.167 & 0.0831 & 0.0093 & 0.0254 & 0.112 & 0.0405 & 0.0254 & -0.0161 & 0.627 \\
\hline 2008 & 0.1017 & -0.0164 & 0.0388 & -0.161 & 0.0873 & 0.0094 & 0.0198 & 0.108 & 0.0409 & 0.0257 & -0.0241 & 0.628 \\
\hline 2009 & 0.0998 & -0.0066 & 0.0345 & -0.066 & 0.0913 & 0.0062 & 0.0095 & 0.068 & 0.044 & 0.0132 & -0.0323 & 0.3 \\
\hline Mean & & & & -0.124 & & & & 0.082 & & & & 0.387 \\
\hline
\end{tabular}


increased over time, while informal elder-care has increasingly reduced female chance to work.

Second, we find that the estimated trends in female labour market participation are related to differences in the labour market institutional setting and in the social policy environment across countries. Such policy and institutional factors play an important role in shaping the labour market opportunities of women by affecting the quality of potential jobs available, the chances to (re-)enter the labour market, and the opportunity costs of employment (vs non-employment). As expected, the estimated effects vary across women with different characteristics, such as type of family care involvement, age and level of education. In particular, the observed positive trend in the attitude to work of women with children appears to be favoured by the expansion of flexible forms of employment which have progressively eased labour market access by reducing entry costs. This positive effect is stronger for women at the early stage of their work life despite the level of education. Generous child and family benefits and maternity/paternity leaves are positively related to women labour market attachment of young mothers, and the effect is stronger for medium to high-educated individuals.

Third, our analysis reveals a positive association between female activity rate and changes of the institutional framework towards the flexicurity model in countries such as Denmark and Netherlands which are characterized by a balanced mix of flexibility and security. The policy implications of this last set of results are clear: reforms of employment protection towards a larger degree of flexibility need to be accompanied by an increase in state-provided security. Such a mix of institutional reforms will guarantee, on the one hand, lower entry costs for individuals with a weaker attachment to work and, on the other, a set of incentives to actively participate to the labour market.

Finally, we provide a quantification of how much of the observed trend in female labour market participation can be attributed to changes in the labour market institutional setting and family policies through a simple decomposition exercise. We find that the mix of institutional and policy changes accounts for almost $25 \%$ of the increase of the labour market participation of young women (around 2.5\% points) and 38\% of the participation of high educated women (around 1.5\% points). Our results also reveal that the changing institutional and policy setting accounts for a lower fraction of the increase in the labour market participation of low-skilled women in Europe.

\section{Endnotes}

${ }^{1}$ In 1997, the Member States of the European Union (EU) unanimously decided to add a new article to the Amsterdam Treaty (Article 13). The new article enabled the Council to take appropriate actions to combat discrimination based on sex, racial or ethnic origin, religion or belief, disability, age or sexual orientation.

${ }^{2}$ This information is retrieved from the OECD labour market statistics, http://stats. oecd.org/.

${ }^{3}$ Algan and Cahuc (2007); Fernandez (2007); Fortin (2005); Giavazzi et al. (2009); Olivetti et al. (2013).

${ }^{4}$ Goodpaster (2010); Leigh (2010); Munasinghe et al. (2008).

${ }^{5}$ Ermisch (2003); Euwals et al. (2011); Goldin (2006); Gustafsson and Kenjoh (2008).

${ }^{6}$ Beaudry and Lemieux (1999); Fitzenberger et al. (2004); Balleer et al. (2009).

${ }^{7}$ Employment in Europe 2001 reports that drop-out rates from employment into unemployment or inactivity are strongly linked to job quality. High levels of involuntary temporary contracts and part-time work are associated with high drop out rates (some 
$15 \%$ into unemployment and 10\% into inactivity). Del Boca et al. (2009) show that the influence of part-time on participation is positive only where part-time jobs are perceived to be of 'high quality'.

${ }^{8}$ With regard to the effect of the presence of an elderly relative on women labour supply, the existing studies have not determined a clear relationship. Wolf and Soldo (1994), estimating simultaneously the choice of employment and elderly care cannot find any negative relationship. Ettner (1995) for the US, Heitmueller and Michaud (2006) for the UK and Casado et al. (2007) for Spain show that co-residing with a disabled senior person has a relevant discouraging effect on participation in the labour market. Chang and White-Means (1995) find that co-residing with the senior person has a negative effect on female participation and that such effect is particularly strong for low-educated women.

${ }^{9} \mathrm{ECHP}$ data were first collected in 1994 , when a sample of 60,500 nationally representative households (i.e. approximately 130,000 adults aged over 16) were interviewed in 12 member states. Austria joined the project in the second wave in 1995, Finland in 1996, and Sweden in 1997. Therefore, since then, the data is covering all EU-15 member states.

${ }^{10}$ In the 2004 wave, EU-SILC covered all EU-15 member states except Germany, Netherlands and the UK. Since 2005, the dataset involves the $25 \mathrm{EU}$ member states, plus Norway and Iceland.

${ }^{11}$ Namely, Austria, Belgium, Denmark, Finland, France, Germany, Greece, Ireland, Italy, Luxembourg, Netherlands, Portugal, Spain, Sweden, United Kingdom.

${ }^{12}$ Technical details can be found in Appendix A.

${ }^{13}$ For each European country and each year between 1994-2000 (ECHP data) and between 2004-2009 (EU-SILC data) we compute the two different indicators and perform $\mathrm{t}$-test statistics to assess significant difference between the beginning and the end of the observed time window. The complete list of results is collected in Additional file 1 Tables S1-S2. For robustness check, we have also performed a t-test for differences between means of the first period (1994-2000 covered by the ECHP survey) and the second period (2004-2009 covered by the EUSILC survey). The results remain qualitatively the same; indeed, when differences appear to be significant using the initial and final year of the sample, they are significant also when using a comparison between means.

${ }^{14}$ In some respect, the presence of an elderly relative in the household can be a better proxy of care burdens than having children. This variable is indeed less affected by endogeneity issues that may arise in the estimation as a consequence of the possible inverse causal relationship between labour market status and the rational choice of having a child (Cipollone and D'Ippoliti 2011).

${ }^{15}$ Not surprisingly, the results for the employment rate are qualitatively the same as those reported for the participation rate, with some differences in the magnitude of the impacts. While activity rates are widely used as an indicator of labour market involvement, it is increasingly recognized that employment and hours worked are the key indicators for assessing female labour market integration (Jonung and Persson 1993). One reason is that female unemployment is often hidden among those defined as inactive because of the low work attachment of women of specific groups (typically low skilled women with young children). Results are available upon request.

${ }^{16}$ Regressions of models (1) and (2) have been run also for the restricted sample of women between 25 and 54 years old. The results remain qualitatively unchanged with respect to those in Tables 3 and 4 .

${ }^{17}$ Note that the reported coefficients should not be interpreted as causal effects, as both participation and fertility may be simultaneous decisions. The direction of the bias is difficult to detect.

${ }^{18}$ This may be due to a number of factors, such as differences in the composition of the labour force and in the institutional setting. In countries where female labour force 
participation is low, women in employment are typically characterized by a higher level of education, implying a stronger labour market attachment. Moreover, labour market institutional rigidities in Southern countries - which make (re)entering the labour market after a period of temporary leave more difficult- may stimulate higher continuity in work attachment. This difficulty in re-entering the market seems to be confirmed by evidence that in the Social Democratic countries (and to a less extent in the Continental countries) mothers' participation and employment increase steadily as the youngest child grows up (mostly through a re-entry to part time employment). In Southern countries, the presence of children negatively affects female labour market participation, even when the child is of school age.

${ }^{19}$ We use a simple linear trend since any different choice would increase the complexity of the model. For example, the use of year dummies in Equation 2 implies to create almost 20 additional interaction term for each individual/family characteristic, for a total of around 240 additional estimated coefficients. Nevertheless, the trend of the aggregate participation rate estimated using year dummies is qualitatively consistent with the one obtained imposing the more parsimonious linear functional form.

${ }^{20}$ In fact, while there is not a substantial difference in the labour market behaviour of women in their mid 20s and 30s (born after the early 1960s and grew up and educated after the feminist movement in the 1970s), for those in their mid 30s and 40s, the participation rate has increased by $11 \%$, and for those older than 45 by almost $20 \%$.

${ }^{21} \mathrm{~A}$ similar characterization of the welfare regimes has been followed by Bertola et al. (2001).

${ }^{22}$ The multilevel method allows the researcher to state what portion of a dependent variable's variance is attributable to state-level versus individual-level variation generated by both observable and unobservable factors. The option of using clustered robust standard errors on standard regressions with interactions to account for the intraclass correlation is a "weaker" form of correction than using a multilevel model. The multilevel model not only accounts for the intraclass correlation, but also corrects the denominator degrees of freedom for the number of clusters. Therefore, the advantage in using multilevel analysis techniques lies in inferential issues by providing more accurate standard errors. Technical details and inferential issues related to the application of the multilevel analysis techniques can be found in Hox (2010).

${ }^{23}$ Principal-Component Analysis (PCA) aims to convert a set of possibly correlated variables into a lower dimensional set of linearly uncorrelated variables called principal components. These relevant factors are then rotated using the varimax method to maximize the procedure's efficiency (Kline (2004)).

${ }^{24}$ The macro factor INST captures (1) the extent of Active and Passive Labour Market Programs (LMPs) and (2) the extent of employment protection legislation (EPL).

Though LMPs can be more properly referred to as labour market policies, in the macro literature, LMPs are often considered as labour market "institutional factors" (see among the others Blanchard and Wolfers 2000; Gomez-Salvador et al. 2004; Nickell et al. 2005; Boeri et al. 2012). Hence, for the sake of brevity, we denominate the overall macro factor which encompasses both aspects of the labour market as INST.

${ }^{25}$ The similarity between the standard definition of flexicurity and our second factor is straightforward. Indeed, the European Commission defines flexicurity as an integrated strategy to simultaneously enhance flexibility and security in the labour market. It is traditionally implemented by means of: 1) flexible and reliable contractual arrangements, which are negatively correlated with employment protection; 2) effective active labour market policies; and 3) modern social security systems providing adequate income support during employment transitions, which are positively correlated with passive labour market policies.

${ }^{26}$ Cipollone and D'Ippoliti (2011) carried out a similar analysis for Italy, exploiting territorial heterogeneity at regional level. 
${ }^{27}$ In particular, for women in the age group (55-64), the "variable co-living with an elderly relative (older than 70)" can simply capture the presence of the partner rather than the presence of a relative in need of care. The coefficients for the specifications in Tables 3 and 4, over the restricted sample of women between 25 and 55 years old (Table 3B and Table 4B) are qualitatively similar to those of the whole sample. Results are available upon request.

${ }^{28} \mathrm{We}$ also explore the possibility of an interaction between welfare policies $(P O L)$ and labour market institutions (INST). Policies aimed to support income may be related to a decrease in participation by increasing the reservation wage. At the same time, income support may reduce the potential impact of reforms of the labour market institutional framework aimed to increase participation. However, our family policy indicator (POL) is too broad to capture clearly the underlying mechanism of action, and the estimated effect of its interaction with the INST indicator would be difficult to interpret. Results are available upon request.

${ }^{29}$ The estimated coefficients on individual controls are consistent with those reported in the previous sessions and and are available from the authors upon request.

${ }^{30}$ Such results may be related to the fact that the indicator $P O L$ includes both in-kind (maternity and paternity leaves, child care facilities ecc.) and monetary (family allowances) transfers. While the former have a positive impact on mothers labour market attachment, the latter may have a negative impact which is stronger for low-income mothers (Del Boca et al. 2009).

${ }^{31}$ Combining the two axes of flexibility and security, Tangian (2007) concludes that only Denmark and Netherlands are developing both dimensions.

${ }^{32}$ See Simonazzi (2009) for a detailed analysis of the recent dynamics of the care sector in the EU countries.

${ }^{33}$ The interplay between flexibility and security in determining labour market performance have been at the forefront of the EU social policy and economic debate in the last decade (European Commission 2012; OECD 2004; OECD 2010). While the labour market effects of the interaction between security and flexibility have been extensively studied from a theoretical point of view (see, for example, Blanchard and Tirole 2008; Boeri et al., 2003), the empirical evidence is still scarce.

${ }^{34}$ This threshold is slightly higher for women with young children (2.05) and lower for women involved in elderly care (1.92).

${ }^{35}$ The flexibility threshold becomes 1.60 and 1.92 for women involved in child care and elderly care respectively.

${ }^{36}$ Notice that the Social Democratic countries (and to less extent the Continental countries) are also those countries for which we estimated the strongest (negative) trend in the effect of young children on female participation (see Table 4).

${ }^{37}$ The Vidgor index (Vidgor, 2008) is derived for a value of $\mathrm{p}=0.5$ and does not explicitly deal with differences between $x$ and $z$ variables.

${ }^{38}$ Algan et al. (2012) use this analysis to study cultural and economic integration patterns of immigrants in Europe.

${ }^{39}$ Through this simplification, we neglect variations on the coefficient estimates due to changes in preferences which are not related to macro-factors. Since our aim is to quantify the role of changes in macro-factors on female decisions, this simplification does not affect our results.

\section{A Appendix 1}

\section{A.1 Vigdor index: methodological framework}

Let us define $D$ to be a binary variable taking the value " 0 " if the individual is in group 0 and " 1 " if he/she is in group 1 . We are interested in assessing differences between group 0 and group 1 using a one-dimensional measure of how different are the distributions of some characteristics $x$ between group 0 and 1 . 
Let us denote by $f_{o}(x)$ the density function of $x$ among group 0 individuals (reference group), and by $f_{1}(x)$ the density function of $x$ among group 1 individuals.

Vigdor (2008) estimates a model for

$$
P(D=1 \mid x)=\frac{p f_{1}(x)}{p f_{1}(x)+(1-p) f_{0}(x)}=\frac{p f_{1}(x)}{f(x)}=\rho(x),
$$

where $p$ is the proportion of group 1 individuals in the population and $f(x)$ is the density function of $x$ in the population. A generalization of the Vidgor index which is between 0 and 1 and is composition invariant (i.e. it does not depend on $p$ ) is

$$
I=2 \int \frac{f_{0}(x) f_{1}(x)}{f_{0}(x)+f_{1}(x)} d x=2 \int \frac{1}{1+g(x)} f_{1}(x) d x
$$

Such an analysis is based on the ratio $g(x)=\frac{f_{1}(x)}{f_{0}(x)}$ which will be equal to 1 if group 0 and 1 have the same distribution of $x$. This implies that any difference in the observed $x$ will result in a discrepancy between group 0 and 1 in the synthetic index.

An important empirical issue is that there might be some characteristics $z$ whose differences between group 0 and 1 are not appropriate to take into consideration and infer a behavioural difference between group 0 and 1 . For example, we do not want to label differences in the age structures between two groups as differences in labour market behaviour between the two groups. The unconditional distribution of $x$ (as in (4)) will be different if individuals in group 0 and 1 have a different distribution of $z$. An analysis based on (4) would be misleading. For example, if group 0 and group 1 are women and men, we do not want to capture differences in labour market performance between women and men due to different gender population structure. Gender demographic trends are correlated to differences in employment, labour market participation or job types, but they are not a matter of research themselves. Therefore, we need to work with the distribution of $x$ given $z$.

Denote by $f_{o}(x \mid z)$ the density function of $x$ given $z$ among group 0 individuals, $f_{1}(x \mid z)$ the density function of $x$ given $z$ among group 1 individuals. Define the marginal distributions of $z$ among group 0 and $1, h_{o}(z)$ and $h_{1}(z)$ respectively. We are thus interested in the ratio between density functions

$$
g(x \mid z)=\frac{f_{1}(x \mid z)}{f_{0}(x \mid z)}=\frac{f_{1}(x, z)}{f_{0}(x, z)} \frac{h_{o}(z)}{h_{1}(z)}
$$

A generalization of the Vidgor index which allows for the presence of $z$ variables, while remaining composition invariant, is ${ }^{37}$

$$
I=2 \int \frac{1}{1+g(x \mid z)} f_{1}(x \mid z) h_{1}(z) d x d z
$$

Empirically, one has to get an estimate of $g(x \mid z)$. One way to proceed is as follows. 
First, estimate a probit model for being an individual of group 1 on $x$ and $z$

$$
P(D=1 \mid x, z)=\frac{p f_{1}(x, z)}{p f_{1}(x, z)+(1-p) f_{0}(x, z)}=\frac{p f_{1}(x, z)}{f(x, z)}=\rho(x, z) .
$$

We can write

$$
\frac{f_{1}(x, z)}{f_{0}(x, z)}=\frac{\rho(x, z)}{[1-\rho(x, z)]} \frac{(1-p)}{p}
$$

Substituting into (5), we have that

$$
g(x \mid z)=\frac{\rho(x, z)}{[1-\rho(x, z)]} \frac{(1-p)}{p} \frac{h_{o}(z)}{h_{1}(z)} .
$$

Second, estimate a probit model for being an individual of group 1 conditional on $z$ alone

$$
P(D=1 \mid z)=\frac{p h_{1}(z)}{p h_{1}(z)+(1-p) h_{0}(z)}=\varphi(z)
$$

We can write

$$
\frac{h_{o}(z)}{h_{1}(z)}=\frac{\varphi(z)}{[1-\varphi(z)]} \frac{(1-p)}{p} .
$$

Substituting into (8) we have that

$$
g(x \mid z)=\frac{\rho(x, z)}{[1-\rho(x, z)]} \frac{[1-\varphi(z)]}{\varphi(z)} .
$$

In short, the relative densities of $x$ conditional on $z$ can be estimated from the predicted probabilities of 2 probit models for being an individual in group 1, one conditional on $x$ and $z$ and the other conditional on $z$ alone.

Having $g(x \mid z)$ on hand, the average value of the transformation $\frac{1}{1+g(x \mid z)}$ across group 1 individuals, will then give the synthetic index $(6)^{38}$.

\section{A.2 Adaptation to our setting}

In our analysis we define $D$ as a dummy taking value 1 if the individual is female (disadvantaged group) and 0 otherwise. We consider two $x$ variables, $x_{k}, k=1,2$ :

$-x_{1}$ : dummy taking value 1 if the individual is inactive, and 0 if active (participation rate); 
- $x_{2}$ : dummy taking value 1 if the active individual is employed, and 0 if unemployed (unemployment rate).

We use as control variables $z$ the individual education level, marital status, partner education, number of children and age.

We thus derive two synthetic indicators (activity index and employment index) for each European country and each year between 1994-2000 (ECHP) and between 2004-2009 (EU-SILC) and we perform t-test statistics to assess any significant difference between the beginning and the end of the observed time window. Tables in Additional file 1 collects the complete list of results.

\section{B Appendix 2}

\section{B.1 An algebraic decomposition}

Let us consider model (3):

$$
y_{i j}^{t}=\beta_{0 j}^{t}+\beta_{11 j}^{t} C H I L D_{i j}^{t}+\beta_{12 j}^{t} E L D E R L Y_{i j}^{t}+\beta_{2} \mathbf{x}_{2 i j}^{t}+\varepsilon_{i j}^{t}
$$

where

$$
\begin{aligned}
& \beta_{0 j}^{t}=\delta_{0}+\delta_{1} I N S T_{j}^{t}+\delta_{2} P O L_{j}^{t}+v_{j}^{t} \\
& \beta_{11 j}^{t}=\gamma_{10}+\gamma_{11} I N S T_{j}^{t}+\gamma_{12} P O L_{j}^{t}+v_{1 j}^{t} \\
& \beta_{12 j}^{t}=\gamma_{20}+\gamma_{21} I N S T_{j}^{t}+\gamma_{22} P O L_{j}^{t}+v_{2 j}^{t}
\end{aligned}
$$

For simplicity of exposition, let us define $\mathbf{x}_{1 i j}^{t}$ as a vector of individual characteristics whose impact depends on macro-factors (which in our model 3 include CHILD and ELDERLY).

We obtain

$$
y_{i j}^{t}=\beta_{0 j}^{t}+\left(\mathbf{x}_{1 i j}^{t}\right) \prime \beta_{1 j}^{t}+\left(\mathbf{x}_{2 i j}^{t}\right) \prime \beta_{2 j}^{t}+\varepsilon_{i j}^{t}
$$

with

$$
\begin{aligned}
& \beta_{0 j}^{t}=\delta_{0}^{t}+\left(\mathbf{z}_{1 i j}^{t}\right) \prime \delta_{1}^{t}+v_{j}^{t} \\
& \beta_{1 j}^{t}=\gamma_{0}^{t}+\left(\mathbf{z}_{1 i j}^{t}\right) \prime \gamma_{1}^{t}+v_{j}^{t}
\end{aligned}
$$

Hence

$$
y_{i j}^{t}=\delta_{0}^{t}+\left(\mathbf{z}_{j}^{t}\right) \prime \delta_{1}^{t}+\left(\mathbf{x}_{1 i j}^{t}\right) \prime \gamma_{0}^{t}+\left(\mathbf{x}_{1 i j}^{t}\right) \prime \gamma_{1}^{t}\left(\mathbf{z}_{j}^{t}\right) \prime+\left(\mathbf{x}_{2 i j}^{t}\right) \prime \beta_{2}^{t}+R_{j t}^{t}
$$

with $\left(\mathbf{x}_{1 i j}^{t}, \beta_{1 j}^{t}, \gamma_{0}^{t}, v_{1 j}^{t}\right)$ as $m \times 1$ vectors; $\left(\mathbf{x}_{2 i j}^{t}, \beta_{2}^{t}\right)$ as $n \times 1$ vectors; $\left(\mathbf{z}_{j}^{t}, \delta_{1}^{t}\right)$ as $p \times 1$ vectors, and $\gamma_{1}^{t}$ as $p \times m$ matrix. The residual $R_{j t}^{t}$ includes both the random component $v_{j}^{t}+$ $\left(\mathbf{x}_{1 i j}^{t}\right) / v_{j}^{t}$ and the error term $\varepsilon_{i j}^{t}$. 
Let us take first-differences

$$
\begin{aligned}
y_{i j}^{t}-y_{i j}^{t-1}= & \left(\delta_{0}^{t}-\delta_{0}^{t-1}\right)+\left[\left(\mathbf{z}_{j}^{t}\right),\left(\delta_{1}^{t}-\delta_{1}^{t-1}\right)+\left(\mathbf{z}_{j}^{t}-\mathbf{z}_{j}^{t-1}\right), \delta_{1}^{t-1}\right] \\
& +\left[\left(\mathbf{x}_{1 i j}^{t}\right) \prime\left(\gamma_{0}^{t}-\gamma_{0}^{t-1}\right)+\left(\mathbf{x}_{1 i j}^{t}-\mathbf{x}_{1 i j}^{t-1}\right) \prime \gamma_{0}^{t-1}\right] \\
& +\left[\left(\mathbf{x}_{2 i j}^{t}\right),\left(\beta_{2}^{t}-\beta_{2}^{t-1}\right)+\left(\mathbf{x}_{2 i j}^{t}-\mathbf{x}_{2 i j}^{t-1}\right), \beta_{2}^{t-1}\right] \\
& +\left[\left(\mathbf{x}_{1 i j}^{t}\right) \prime\left(\gamma_{\mathbf{1}}^{\mathbf{t}}-\gamma_{\mathbf{1}}^{\mathbf{t}-\mathbf{1}}\right) / \mathbf{z}_{j}^{t}+\left(\mathbf{x}_{1 i j}^{t}\right),\left(\gamma_{\mathbf{1}}^{\mathbf{t}-\mathbf{1}}\right) / \mathbf{z}_{j}^{t}-\left(\mathbf{x}_{1 i j}^{t-1}\right),\left(\gamma_{1}^{\mathbf{t}-\mathbf{1}}\right) / \mathbf{z}_{j}^{t-1}\right] \\
& +\left[R_{j i}^{t}-R_{j t}^{t-1}\right]
\end{aligned}
$$

Model (12) is equivalent to Stoker (1985), which decomposes the change of an aggregate variable (here the proportion of women who participate) into a change of the behavioural micro model (coefficients of (11) for a series of cross-sections) and a change in the distribution of the micro variables (education, fertility, marital status, etc.). Since our aim is to quantify the role of changes in macro-factors on female decisions, we impose that the coefficient estimates of model (12) do not vary over time. In this way, we are able to use our multilevel model (3) to determine what portions of changes in behaviour over time depends on changes in policy regulations ${ }^{39}$. In other words, we apply the following restrictions to model (12):

- $\delta_{0}^{t}=\delta_{0}^{t-1}=\bar{\delta}_{0}$;

- $\boldsymbol{\beta}_{2}^{t}=\boldsymbol{\beta}_{2}^{t-1}=\overline{\boldsymbol{\beta}}_{2}$;

- $\gamma_{0}^{t}=\gamma_{0}^{t-1}=\bar{\gamma}_{0}$;

- $\gamma_{1}^{t}=\gamma_{1}^{t-1}=\bar{\gamma}_{1}$

- $\delta_{1}^{t}=\delta_{1}^{t-1}=\bar{\delta}_{1}$

- $\delta_{0}^{t}=\delta_{0}^{t-1}=\bar{\delta}_{0}$.

The simplified model is

$$
\begin{aligned}
y_{i j}^{t}-y_{i j}^{t-1}= & {\left[\left(\mathbf{x}_{2 i j}^{t}-\mathbf{x}_{2 i j}^{t-1}\right), \overline{\boldsymbol{\beta}}_{2}\right] } \\
& +\left[\left(\mathbf{z}_{j}^{t}-\mathbf{z}_{j}^{t-1}\right), \overline{\boldsymbol{\delta}}_{1}+\left(\mathbf{z}_{j}^{t}-\mathbf{z}_{j}^{t-1}\right) \overline{\boldsymbol{\gamma}}_{1}\left(\mathbf{x}_{1 i j}^{t-1}\right)\right] \\
& +\left[\left(\mathbf{x}_{1 i j}^{t}-\mathbf{x}_{1 i j}^{t-1}\right) \overline{\boldsymbol{\gamma}}_{0}+\left(\mathbf{z}_{1 i j}^{t}\right) \overline{\boldsymbol{\gamma}}_{1}\left(\mathbf{x}_{1 i j}^{t}-\mathbf{x}_{1 i j}^{t-1}\right)\right] \\
& +\left[R_{j t}^{t}-R_{j i}^{t-1}\right]
\end{aligned}
$$

$\equiv \Delta$ individual characteristics $\mathbf{x}_{2}$ whose effect does not depend on macro factors $z$

$+\Delta$ in macro factors $z$

$+\Delta$ individual characteristics $\mathbf{x}_{1}$ whose effect depends on macro factors $z$

$+\Delta$ residual component

\section{Additional file}




\section{Competing interests}

The IZA Journal of European Labor Studies is committed to the IZA Guiding Principles of Research Integrity. The authors declare that they have observed these principles.

\section{Acknowledgments}

This work was conducted as part of the of the project 'Employment 2025: How will multiple transitions affect the European labour market (NEUJOBS)', funded under the 7th FP of the European Commission (Grant Agreement: 266833). We thank Anton Hemerijck, Anne Gauthier, Emanuele Ciani and the participants to the NEUJOBS meetings and events for their valuable comments and suggestions.

Responsible editor: Sara de la Rica

\section{Author details}

${ }^{1}$ LUISS University and CeLEG, Rome, Italy. ${ }^{2}$ Cornell University, EIEF, CEPR and IZA, Ithaca NY, USA. ${ }^{3}$ LUISS University, LLEE and CeLEG, Rome, Italy.

\section{Received: 5 December 2013 Accepted: 23 April 2014}

Published: 29 Sep 2014

\section{References}

Algan Y, Cahuc P (2007) The roots of low European employment: family culture? In: Pissarides C, Frenkel J (eds) NBER International Seminar on Macroeconomics 2005. MIT Press, Cambridge, pp 65-109

Algan Y, Bisin A, Manning A, Verdier T (eds) (2012) Cultural integration of immigrants in Europe. Oxford University Press, Oxford

Balleer A, Gomez-Salvador R, Turunen J (2009) Labor force participation in the Euro area: a cohort based analysis. Working Paper Series No.1049, European Central Bank

Beaudry P, Lemieux T (1999) Evolution of the female labor force participation rate in Canada, 1976-994: a cohort analysis Canadian Business Economics 7(2): 57-70

Bertola G, Jimeno JF, Marimon R, Pissarides C (2001) EU welfare systems and labour markets: diverse in the past, integrated in the future? In: Bertola G, Boeri T, Nicoletti G (eds) Welfare and employment in a united Europe. MIT Press, Cambridge, MA, USA, pp 23-122

Blanchard O, Landier A (2002) The perverse effects of partial labor market reform: fixed-term contracts in France. Econ J R Econ Soc 112(480): F214-F244

Blanchard O, Wolfers J (2000) The role of shocks and institutions in the rise of European unemployment: the aggregate evidence. Econ J R Econ Soc 110(462): C1-33

Blanchard O, Tirole J (2008) The Joint Design of Unemployment Insurance and Employment Protection: A First Pass. J Eur Econ Assoc 6(1): 45-77

Boeri T, Conde-Ruiz Jl, Galasso V (2012) The political economy Of flexicurity. J Eur Econ Assoc Eur Econ Assoc 10(4): 684-715

Boeri T, Conde-Ruiz J, Galasso V (2003) Protecting Against Labor Market Risk: Employment Protection or Unemployment Benefits. CEPR Discussion Paper No. 3999, C.E.P.R. Discussion Papers

Casado D, García P, López A (2007) Informal Care and labor Force Participation among Middle-Aged Women in Spain. Economics Working Papers 1023, Department of Economics and Business, Universitat Pompeu Fabra

Chang C, White-Means S (1995) Labor supply of informal care-givers. Int Rev Appl Econ 9(2): 192-205

Cipollone A, D'Ippoliti C (2011) Women's employment: joining explanations based on individual characteristics and on contextual factors. Am J Econ Sociol Wiley Blackwell 70(3): 756-783

Costa Dora L (2000) From Mill Town to Board Room: The Rise of Women's Paid Labor. J Econ Pespect 4: 101-122

Del Boca D, Locatelli M (2006) The Determinants of Motherhood and Work Status: A Survey. IZA Discussion Papers 2414, Institute for the Study of Labor (IZA)

Del Boca D, Pasqua S, Pronzato C (2009) Motherhood and market work decisions in institutional context: a European perspective. Oxford Econ Papers 61: i147-i171

Ermisch J (2003) Does a 'teen-birth' have longer-term impacts on the mother? suggestive evidence from the British Household Panel Study. ISER Working Paper Series 2003-32, Institute for Social and Economic Research

Ermisch J, Wright R (1993) Wage offers and full-time and part-time employment by British women. J Hum Resour 28(1): 111-33

Ettner SL (1996) The opportunity costs of elder care. J Hum Resour 31(1): 189-205

Ettner SL (1995) The impact of "parent care" on female labor supply decisions. Demography 32: 63-80

European Commission (2012) Evaluation of flexicurity 2007-2010: Final Report. Directorate-General Employment, Social 987 Affairs and Equal Opportunities 988. http://ec.europa.eu/social/BlobServlet?docld=10018\&langld=en

Euwals R, Knoef M, van Vuuren D (2011) The trend in female labor force participation: what can be expected for the future? Empir Econ 40: 729-753

Fernandez R (2007) Women, work, and culture. J Eur Econ Assoc 5(2-3): 305-332

Ferrera M (1996) The "Southern" model of welfare in social Europe. J Eur Soc Policy 6(1): 17-37

Fitzenberger B, Schnabel R, Wunderlich G (2004) The gender gap in labor market participation and employment: a cohort analysis for West Germany. J Popul Econ 17: 83-116

Fortin N (2005) Gender role attitudes and women's labor market outcomes across OECD countries. Oxford Rev Econ Policy 21(3): 416-438

Gauthier AH (2011a) Comparative Family Policy Database, Version 3 [computer file]. Netherlands Interdisciplinary Demographic Institute and Max Planck Institute for Demographic Research (distributors). Retrieved from: http:// www.demogr.mpg.de/en/ 
Gauthier AH (2011b) Comparative Maternity, Parental, and Childcare Leave and Benefits Database (1960-2010) [computer file]. Netherlands Interdisciplinary Demographic Institute and Max Planck Institute for Demographic Research (distributors). Retrieved from: www.demogr.mpg.de

Genre V, Gomez-Salvador R, Lamo A (2010) European women: why do(n't) they work. Appl Econ 42(12): $1499-1514$

Giavazzi F, Schiantarelli F, Serafinelli M (2009) Culture, Policies and Labor Market Outcomes. NBER Working Paper Series 15417, National Bureau of Economic Research, Inc

Gomez-Salvador R, Messina J, Vallanti G (2004) Gross job flows and institutions in Europe. Labour Econ Elsevier 11(4): 469-485

Goodpaster NK (2010) Leaves and leaving: the family and medical Leave act and the decline in maternal labor force participation. B.E. J Econ Anal Policy 10(1). Art.6

Guell M, Petrongolo B (2007) How binding are legal limits? transitions from temporary to permanent work in Spain. Labor Econ Elsevier 14(2): 153-183

Gustafsson S, Kenjoh E (2008) The Timing of Maternity. In: Del Boca D, Wetzles C (eds) Social Policies, Labor Markets and Motherhood. Cambridge University Press, Cambridge, pp 182-224

Heckman J, Pages C (2000) The Cost of Job Security Regulation: evidence from Latin American labor markets. NBER Working Paper Series 7773, National Bureau of Economic Research, Inc

Heitmueller A (2007) The chicken or the egg? Endogeneity in labor market participation of informal carers in England. J Health Econ Elsevier 26(3): 536-559

Heitmueller A, Michaud P (2006) Informal Care and Employment in England: Evidence from the British Household Panel Survey. IZA Discussion Papers 2010, Institute for the Study of Labor (IZA)

Hodrick R, Prescott EC (1997) Postwar U.S. business cycles: an empirical investigation. J Money Credit Banking 29(1): 1-16

Hox JJ (2010) Multilevel analysis : techniques and applications - 2nd ed. Routledge: New York and Hove, New York

Jaumotte F (2003) Female labor force participation. Past trends and main determinants in OECD countries. OECD Econ Studies 37: $52-108$

Jonung C, Persson I (1993) Women and Market Work: the misleading tale of participation rates in international comparisons. Work Employ Soc 7(2): 259-274

Keck W, Saraceno C (2010) Caring for a parent while working for pay in the German welfare regime. Int J Ageing and Later Life 5(1): 107-138

Kline P (2004) An easy guide to factor analysis. Routledge, London

Lefebvre P, Merrigan P, Verstaete M (2009) Dynamic labor supply effects of childcare subsidies: Evidence from a Canadian natural experiment on low-fee universal. Labor Econ 16(5): 490-502

Leigh A (2010) Informal care and labor market participation. Labor Econ 17(1): 140-49

Leitner S (2003) Varieties of Familialism: The Caring Function of the Family in Comparative Perspective. Eur Soc 5(4): 353-375

Munasinghe L, Reif T, Henriques A (2008) Gender gap in wage returns to job tenure and experience. Labor Econ 15(6): 1296-316

Nardo M, Saisana M, Saltelli A, Tarantola S, Hoffman A, Giovannini E (2005) Handbook on constructing composite indicators: methodology and user guide. OECD Statistics Working Papers, n. 2005/3, Paris

Nickell S, Nunziata L, Ochel W (2005) Unemployment in the OECD Since the 1960s. What do we know? Econ J R Econ Soc 115(500): 1-27

Nicoletti G, Scarpetta S, Boylaud O (1999) Summary indicators of product market regulation with an extension to employment protection legislation. OECD Economic Department Working Papers, n. 229, Paris

OECD (2010) Chapter 3, Employment Outlook. OECD, Paris

OECD (2004) Chapter 2, Employment outlook. OECD, Paris

Olivetti C, Patacchini E, Zenou Y (2013) Mothers, friends and gender identity. NBER Working Paper Series 19610, National Bureau of Economic Research, Inc

Sánchez-Mangas R, Sánchez-Marcos V (2008) Balancing family and work: The effect of cash benefits for working mothers. Labor Econ 15(6): 1127-42

Saraceno C (2010) Social Inequalities in Facing Old-Age Dependency: A Bi-Generational Perspective. J Eur Soc Policy 20(1): 32-44

Saraceno C, Naldini M (2007) Sociologia della famiglia. Ed. II Mulino, Bologna

Simonazzi A (2009) New skills for new jobs? Status quo and perspectives for the elderly care sector in Europe. EEO Thematic Paper, European Employment Observatory. http://www.eu-employment-observatory.net/resources/ reports/NewSkillsForNewJobs-ElderlyCareSector-SIMONAZZI.pdf

Stoker TM (1985) Aggregation, structural change, and cross-section estimation. J Am Stat Assoc 80: 720-29

Tangian A (2007) European flexicurity: concepts, methodology and policies. Transfer 3(4): 551-573

Vigdor JL (2008) Measuring immigrant Assimilation in the United States. Civic Report 53, Center for Civic Innovation Manhattan Institute for Policy Research. http://www.manhattan-institute.org/html/cr_53.htm

Ward C, Dale A (1992) Geographical variation in female labour force participation: an application of multilevel modelling. Regional Stud 26: 243-255

Wolf DA, Soldo BJ (1994) Married women's allocation of time to employment and care of elderly parents. J Hum Resour 29(4): 1259-76

10.1186/2193-9012-3-18

Cite this article as: Cipollone et al:: Female labour market participation in Europe: novel evidence on trends and

shaping factors. IZA Journal of European Labor Studies 2014, 3:18 